This item was submitted to Loughborough's Research Repository by the author.

Items in Figshare are protected by copyright, with all rights reserved, unless otherwise indicated.

\title{
Hybrid machining process: experimental and numerical analysis of hot ultrasonically assisted turning
}

PLEASE CITE THE PUBLISHED VERSION

https://doi.org/10.1007/s00170-018-2087-6

\section{PUBLISHER}

(c) Springer

\section{VERSION}

AM (Accepted Manuscript)

\section{PUBLISHER STATEMENT}

This work is made available according to the conditions of the Creative Commons Attribution-NonCommercialNoDerivatives 4.0 International (CC BY-NC-ND 4.0) licence. Full details of this licence are available at: https://creativecommons.org/licenses/by-nc-nd/4.0/

\section{LICENCE}

CC BY-NC-ND 4.0

\section{REPOSITORY RECORD}

Muhammad, Riaz, Naseer Ahmed, Himayat Ullah, Anish Roy, and Vadim V. Silberschmidt. 2019. "Hybrid Machining Process: Experimental and Numerical Analysis of Hot Ultrasonically Assisted Turning”. figshare. https://hdl.handle.net/2134/33800. 


\title{
Hybrid machining process: experimental and numerical analysis of hot ultrasonically assisted turning
}

\author{
Riaz Muhammad $^{1} \cdot$ Naseer Ahmed ${ }^{1} \cdot$ Himayat Ullah $^{2} \cdot$ Anish Roy $^{3} \cdot$ Vadim V. Silberschmidt $^{3}$
}

\begin{abstract}
A hybrid turning is presented for turning of Ti-15V-3 Al-3 Cr-3 Sn alloy. In this technique, cutting insert is vibrated in velocity direction with the help of ultrasonic transducer and external heat is provided to the machined workpiece to gain collective benefits of both arrangements in cutting of hard-to-cut alloys. The studied alloy was investigated numerically and experimentally using hybrid turning process to determine its rewards in decline of measured cutting forces and enhancement in quality of machined surface. The assessment for thermal evolution in the cutting process was carried out both numerically and experimentally, and an accurate prediction of process zone temperatures is achieved. A significant improvement in dry turning of the studied alloy was achieved in terms of substantial decline in cutting forces and no substantial alterations in the metallurgy of the tested material. An elastoplastic thermo-mechanically coupled finite-element model for oblique-turning process is established to investigate the effect of heat and vibration on output parameters numerically. The developed model was used to explore the influence of selected machining parameters (depth-of-cut, feed rate, cutting speed, and tool nose radius) on three components of forces, stresses, and process zone temperature. Comparative case studies were executed with the developed models of conventional-turning, hot-conventional-turning, and hybrid turning and were confirmed by the outputs from tests carried out on the in house prototype available at Loughborough University, United Kingdom. The model was used for two-dimensional ultrasonic vibration in all three axis and resulted no significant drop in the cutting forces when compared to the studied hybrid turning process.
\end{abstract}

Keywords Finite element $\cdot$ Hybrid machining $\cdot$ Turning $\cdot$ Machining $\cdot$ Titanium

\section{Introduction}

Component weight reduction, increased resistance to corrosion and thermo-mechanical fatigue, has become the driving

- A hybrid machining technique is introduced for the machining of beta titanium alloy.

- This technique resulted significant reduction in cutting forces and improvement in surface roughness.

- Experimental results were validated with the developed finite element model.

Riaz Muhammad

R.Muhammad@cecos.edu.pk; R.Muhammad@outlook.com

1 Department of Mechanical Engineering, CECOS University of IT and Emerging Sciences, Peshawar, KPK, Pakistan

2 CESAT, H 11/4, Islamabad, Pakistan

3 Wolfson School of Mechanical, Electrical and Manufacturing Engineering, Loughborough University, Loughborough, Leicestershire LE11 3TU, UK force in aerospace and biomedical industries. In this field, titanium alloys offer clear advantages when compared to steel components. They have comparable strength with modern steels at approximately half the density and excellent fatigue performances and resistance to aggressive environments [1]. At the same time, they are not affected by the shortcomings which are commonly observed in composite materials: low resistance to impact and excessively complicated mechanical behavior. Ti-based materials offer great cost reductions by extending life of components and reducing the operative costs which, in aerospace industry, are also closely linked to weight.

Titanium and its alloys are, however, known for their machining difficulties [2]. Their excessive chemical reactivity and truncated thermal conductivity at elevated temperatures result in need to use specialized cutting tools which are observed anyway to have a shortened life in conventional machining operations [3]. This leads to the need to machine with reduced cutting speed and feeds, with an increase of the machining time and consequently of per-component costs. In addition, Ti-alloy Young's modulus is generally low when 
Table 1 Properties of Ti-15333 [20, 25]

\begin{tabular}{ll} 
Workpiece material & Ti-15 V-3 Al-3 Cr-3 \\
\hline Diameter, $D(\mathrm{~m})$ & 0.065 \\
Length, $L(\mathrm{~m})$ & 0.5 \\
Modulus of elasticity, $E(\mathrm{GPa})$ & 87 \\
Yielding-strength, $\sigma_{y}[\mathrm{~Pa}]$ & $558.85 \mathrm{e} 6$ \\
Density, $\rho\left(\frac{\mathrm{kg}}{\mathrm{m} 3}\right)$ & 4900 \\
Thermal cond., $k\left(\frac{W}{K m}\right)$ & 8.10 \\
Thermal expansion co-efficient $\alpha\left[\frac{1}{K}\right]$ & $8.4 \mathrm{e} 6$ \\
Specific-heat, $C_{p}\left[\frac{J}{g}-^{\circ} \mathrm{C}\right]$ & 0.6 \\
Ultimate strength, $\sigma_{u l}(\mathrm{~Pa})$ & $1200 \mathrm{e} 6$ \\
\hline
\end{tabular}

compared to that of steels. This leads to spring-back and chatter during the machining operations resulting in poor surface integrity with the need of expensive post-processing of the finished components [4]. At low cutting speeds, these alloys produce long continuous chips, entangling on the cutting tool, thus rendering automated machining impossible [5].
Table 2 Feed-speed-depth of cuts used in experimental tests and simulations [25]

\begin{tabular}{ll}
\hline Tested parameters & Magnitude \\
\hline Machining speed; $V(\mathrm{~m} / \mathrm{min})$ & $10,20,30,40,50,60$, and 70 \\
Depth-of-cut; $a_{p}(\mathrm{~mm})$ & $0.1,0.2,0.3,0.4$, and 0.5 \\
Feed rate; $f_{r}(\mathrm{~mm} / \mathrm{rev})$ & 0.1 \\
Initial workpiece temperature; $T\left({ }^{\circ} \mathrm{C}\right)$ & $20,100,200$, and 300 \\
Freq. in HT; $f(\mathrm{~Hz})$ & 20,000 \\
Amp. in HT; $a(\mathrm{~mm})$ & 0.08 \\
\hline
\end{tabular}

Several attempts were made for the titanium and its alloy machinability enhancement, either by improving the characteristics of the alloy or by improving the cutting process. Improving the machining properties of the alloy without degradation of its desirable mechanical properties is challenging as minute changes in the chemical composition have large effects [6-8]. Several efforts have been exercised to shrink the propensity of the alloy for
Fig. 1 a Block diagram and b HT setup [25]
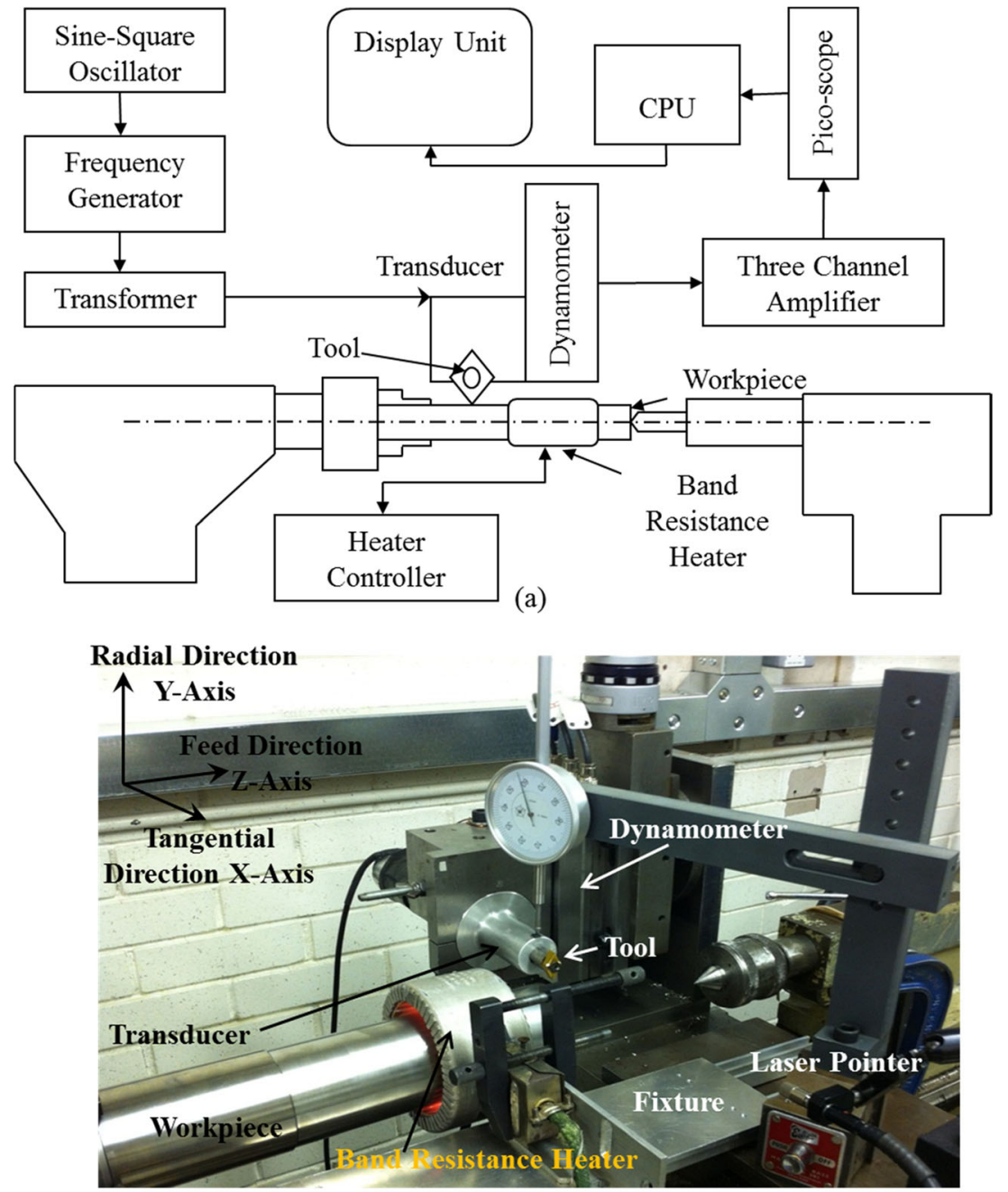

(b) 
Fig. 2 Recorded forces at $300{ }^{\circ} \mathrm{C}$ $\left(V=10 \mathrm{~m} / \mathrm{min} ; a_{p}=0.3 \mathrm{~mm}\right)$ [25]

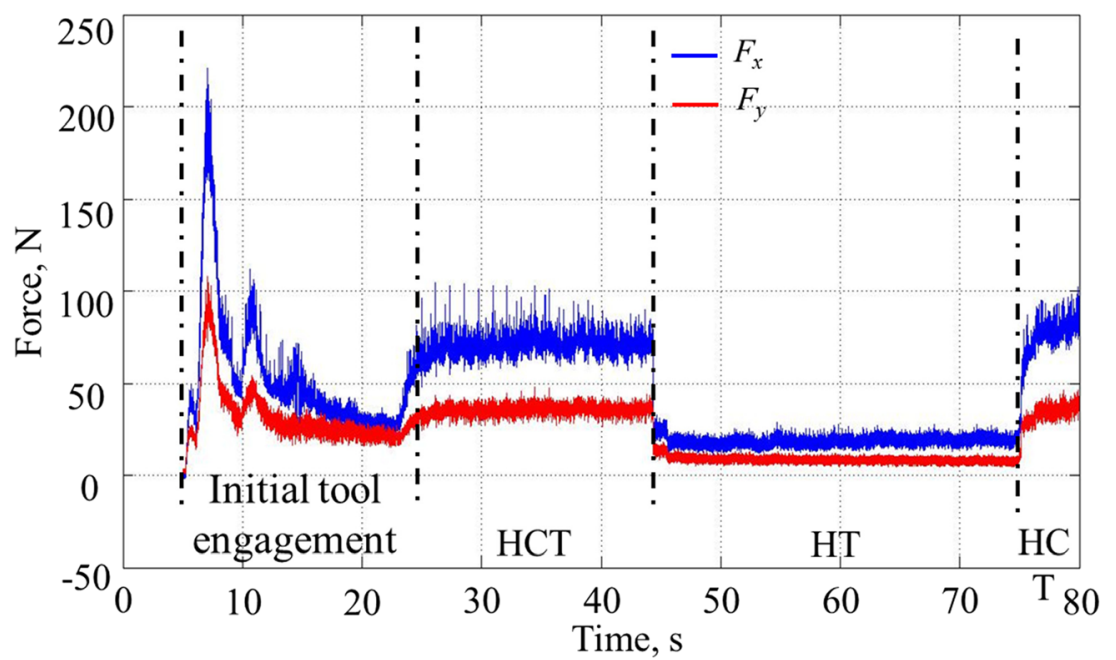

continuous chips by doping of different alloying elements which should decrease adhesion between chip segments, resulting in discontinuous chips. Improving the cutting process offers the guarantee that fatigue and mechanical properties of the alloy are generally preserved. Cooling and lubrication improvements by high-pressure coolant flow generally offer limited advantages due to the high contact pressure between chip and tool and low thermal conductivity of the alloy [9]. Additionally, high costs involved with environmentally friendly disposal of spent fluids reduce the attractive of those techniques to the extent that some researcher claimed costs associated with cutting tools are comparable to those of cutting fluids $[10,11]$. Similarly, improvements of the cutting process by means of hybrid machining techniques [12] or vibration-assisted machining were proven to offer significant advantages when compared to conventional dry machining processes $[13,14]$.
While known from more than four decades, ultrasonically assisted machining has only recently developed enough to be introduced commercially by DMG-Mori Seiki. Additionally, in recent decades, improvements in the efficiency and operative life of ceramic transducers allowed a developed machining system called Ultrasonically-Assisted-Turning (UAT) [15]. In this dry technique, a hard tool is subject to high-frequency vibration preferentially in the cutting direction and resulted in several documented improvements in machining of headstrong alloys [16-23].

The most striking effect reported was the pronounced decline in the levels of observed forces with forced vibrated tool [24, 25]. The consequent reduction of chatter and spring-back observed improved dimensional accuracy of the finished components. Similarly, a significant enhancement in surface finish was also measured [20].
Fig. 3 Process zone temperature history at $0.3 \mathrm{~mm}$ depth of cut, $10 \mathrm{~m} / \mathrm{min}$ cutting speed; a HCT and $\mathbf{b}$ HT

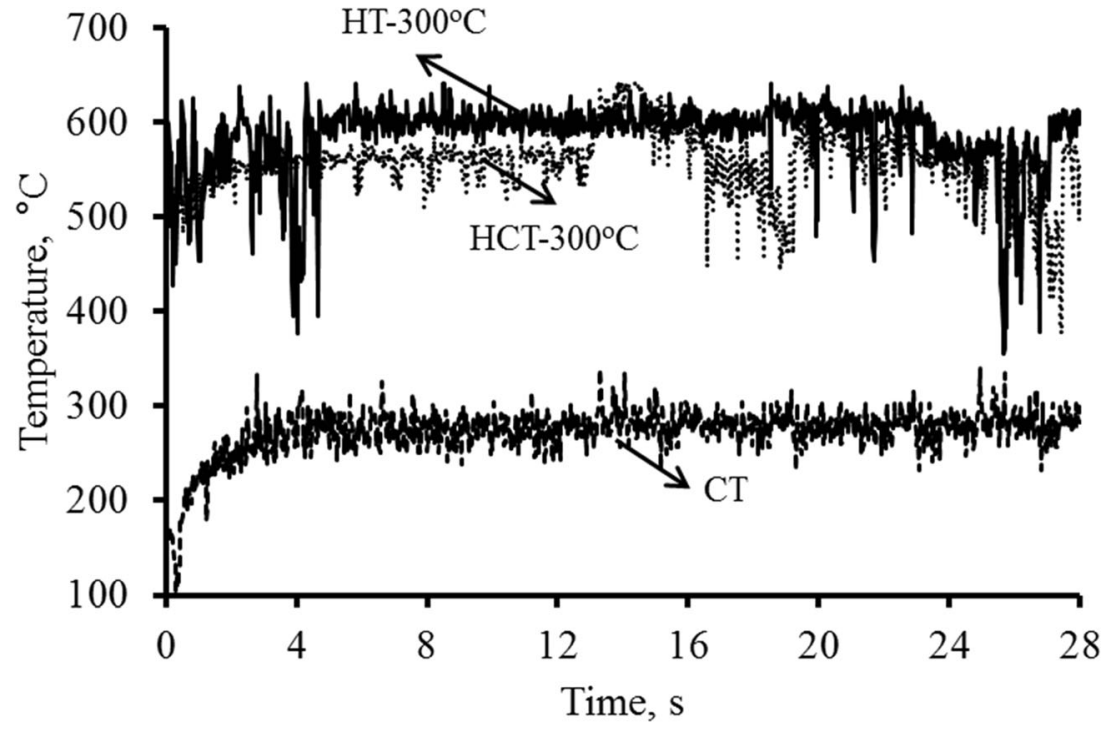




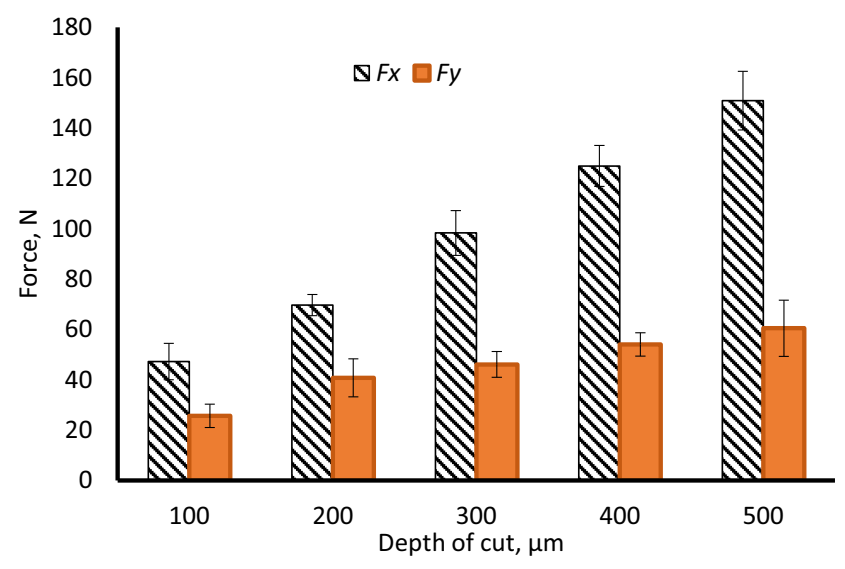

Fig. 4 Level of cutting forces in CT at a cutting speed of $10 \mathrm{~m} / \mathrm{min}$ and various depth of cuts

In the current work, Ti-15 V-3 Al-3 Cr-3 Sn (named as Ti15333) was machined with a novel machining technique called hybrid turning (HT) process, to investigate its effects on the machining operations and demonstrated the observed enhanced surface quality with further decline in insert forces as related to Conventional-Turning (CT) and HotConventional-Turning (HCT). Furthermore, a 3D parametric finite element (FE) model was generated for investigating the load and response of the material on the cutting insert at different tested conditions. The model has the capability to be used for the prediction of forces, temperature, and stresses in unidirectional and $2 \mathrm{D}$ vibration-assisted turning.

\section{Experimental details}

\subsection{Workpiece and cutting tool}

An aged and solution treated, Ti-15333 alloy bar ingot having a $0.5 \mathrm{~m}$ length and diameter of $0.065 \mathrm{~m}$ was used in the tests. An ephemeral description of the properties of the studied alloy is listed in Table 1.

The binary coated DNMG 150608 MF1 CP500 inserts provided by SECO were used in tests as proposed for cutting depths, ranges from 0.2 to $0.3 \mathrm{~mm}$ with 0.05 to $0.25 \mathrm{~mm} / \mathrm{rev}$ feed rate and $45 \mathrm{~m} / \mathrm{min}$ speed in machining of high-strength alloys.

\subsection{Cutting force measurement}

Experimental studies were conducted on universal Harrision M-300 Lathe machine for CT, HCT, and HT. To capture the resulting forces, a Kistler piezo-electric dynamometer (KIAGSWISS/Type9257A) was used. The dynamometer has the capability to measure two components of forces $F_{x}$ (tangential component) and $F_{y}$ (radial component) with a sensitivity of \pm $0.1 \mathrm{~N}$ as shown in Fig. 1. To monitor the vibrational parameters in experimentations, a LASER vibrometer manufactured by Poltec-GmbH was used.

The workpiece was encapsulated by a band resistance heater to apply external heat to it $\left(300{ }^{\circ} \mathrm{C} \pm 10{ }^{\circ} \mathrm{C}\right)$. A

Table 3 Experimental cutting forces in HCT and HT

\begin{tabular}{|c|c|c|c|c|c|c|c|c|c|c|c|}
\hline Depth of cuts $(\mu \mathrm{m})$ & $\begin{array}{l}\text { Workpiece temperature } \\
\left({ }^{\circ} \mathrm{C}\right)\end{array}$ & \multicolumn{2}{|l|}{$\operatorname{HCT}(\mathrm{N})$} & \multicolumn{2}{|l|}{ HT $(\mathrm{N})$} & \multicolumn{2}{|c|}{$\begin{array}{r}\text { Reduction }(\%) \\
\text { CT vs HCT }\end{array}$} & \multicolumn{2}{|c|}{$\begin{array}{r}\text { Reduction (\%) } \\
\text { HCT vs HT }\end{array}$} & \multicolumn{2}{|c|}{$\begin{array}{c}\text { Reduction }(\%) \\
\text { CT vs HT }\end{array}$} \\
\hline$a_{p}$ & $T$ & $F_{x}$ & $F_{y}$ & $F_{x}$ & $F_{y}$ & $F_{x}$ & $F_{y}$ & $F_{x}$ & $F_{y}$ & $F_{x}$ & $F_{y}$ \\
\hline 100 & 100 & $39 \pm 1$ & $24 \pm 3$ & $7 \pm 1$ & $4 \pm 1$ & 16.5 & 5.8 & 82.0 & 83.3 & 84.8 & 83.6 \\
\hline 200 & 100 & $63 \pm 6$ & $35 \pm 3$ & $13 \pm 2$ & $7 \pm 1$ & 9.3 & 12.9 & 79.3 & 80.0 & 80.9 & 82.4 \\
\hline 300 & 100 & $90 \pm 8$ & $42 \pm 5$ & $20 \pm 2$ & $9 \pm 2$ & 8.4 & 8.7 & 77.7 & 78.5 & 79.3 & 80.0 \\
\hline 400 & 100 & $121 \pm 10$ & $47 \pm 5$ & $28 \pm 2$ & $13 \pm 2$ & 3.0 & 11.6 & 76.8 & 72.3 & 77.8 & 76.2 \\
\hline 500 & 100 & $144 \pm 10$ & $52 \pm 6$ & $36 \pm 3$ & $16 \pm 2$ & 4.3 & 14.5 & 75.0 & 69.2 & 75.9 & 73.6 \\
\hline 100 & 200 & $34 \pm 4$ & $23 \pm 2$ & $7 \pm 2$ & $4 \pm 1$ & 27.7 & 9.2 & 79.4 & 82.6 & 85.8 & 85.0 \\
\hline 200 & 200 & $58 \pm 6$ & $28 \pm 3$ & $10 \pm 2$ & $6 \pm 2$ & 15.7 & 29.7 & 82.7 & 78.5 & 85.2 & 84.0 \\
\hline 300 & 200 & $87 \pm 7$ & $38 \pm 4$ & $19 \pm 2$ & $8 \pm 2$ & 11.4 & 17.2 & 78.1 & 76.3 & 80.4 & 82.6 \\
\hline 400 & 200 & $118 \pm 8$ & $41 \pm 6$ & $24 \pm 3$ & $11 \pm 2$ & 5.6 & 23.7 & 79.7 & 73.1 & 80.9 & 79.2 \\
\hline 500 & 200 & $141 \pm 10$ & $49 \pm 6$ & $30 \pm 3$ & $12 \pm 2$ & 6.3 & 18.6 & 78.7 & 75.5 & 80.1 & 79.6 \\
\hline 100 & 300 & $34 \pm 4$ & $18 \pm 3$ & $3 \pm 1$ & $2 \pm 1$ & 28.1 & 30.4 & 91.1 & 88.8 & 94.3 & 91.7 \\
\hline 200 & 300 & $59 \pm 5$ & $26 \pm 3$ & $10 \pm 2$ & $5 \pm 2$ & 15.1 & 35.3 & 83.0 & 80.7 & 85.4 & 87.2 \\
\hline 300 & 300 & $77 \pm 5$ & $35 \pm 4$ & $16 \pm 2$ & $7 \pm 2$ & 20.9 & 23.4 & 79.2 & 77.1 & 83.2 & 84.7 \\
\hline 400 & 300 & $105 \pm 7$ & $38 \pm 5$ & $21 \pm 3$ & $10 \pm 2$ & 15.3 & 28.2 & 80.0 & 73.6 & 83.0 & 81.1 \\
\hline 500 & 300 & $140 \pm 6$ & $44 \pm 6$ & $27 \pm 3$ & $11 \pm 3$ & 7.1 & 26.2 & 80.7 & 75.0 & 81.7 & 80.4 \\
\hline \multicolumn{12}{|c|}{ Cutting forces for CT } \\
\hline Depth of cuts $(\mu \mathrm{m})$ & & 100 & & 200 & & 300 & & 400 & & 500 & \\
\hline$F_{x}$ & & $47 \pm 7$ & & $69 \pm 4$ & & $98 \pm 8$ & & $124 \pm 8$ & & $150 \pm 1$ & \\
\hline$F_{y}$ & & $25 \pm 4$ & & $40 \pm 7$ & & $46 \pm 5$ & & $54 \pm 4$ & & $60 \pm 11$ & \\
\hline
\end{tabular}



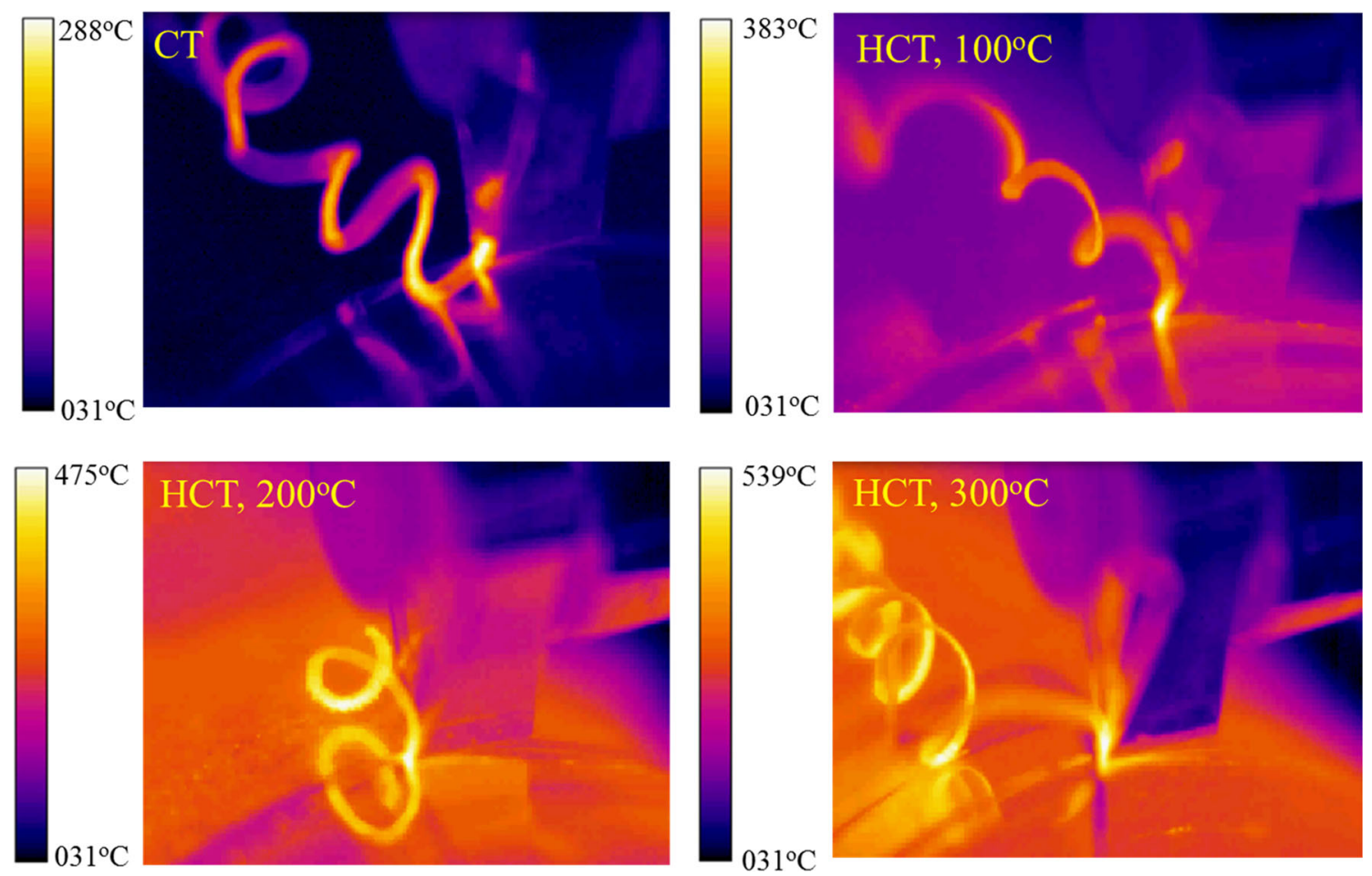

Fig. 5 Thermal analysis of the process zone in CT and HCT $\left(V=10 \mathrm{~m} / \mathrm{min} ; a_{p}=0.3 \mathrm{~mm}\right)$

standardized K-type thermo-couple coated by Teflon and a FLIR ThermaCAMTM SC-3000 infra-red system was used to calculate workpiece temperature during HT. The feedback system imbedded in the controller of the heater ensured accurate prediction of the workpiece surface temperature and was also validated using the FLIR ThermaCAM ${ }^{\mathrm{TM}} \mathrm{SC}-3000$ system.

Table 2 presents the cutting conditions used in experimentations. The listed levels of temperature were chosen based on the metallographic reaction of Ti-15333 to the applied
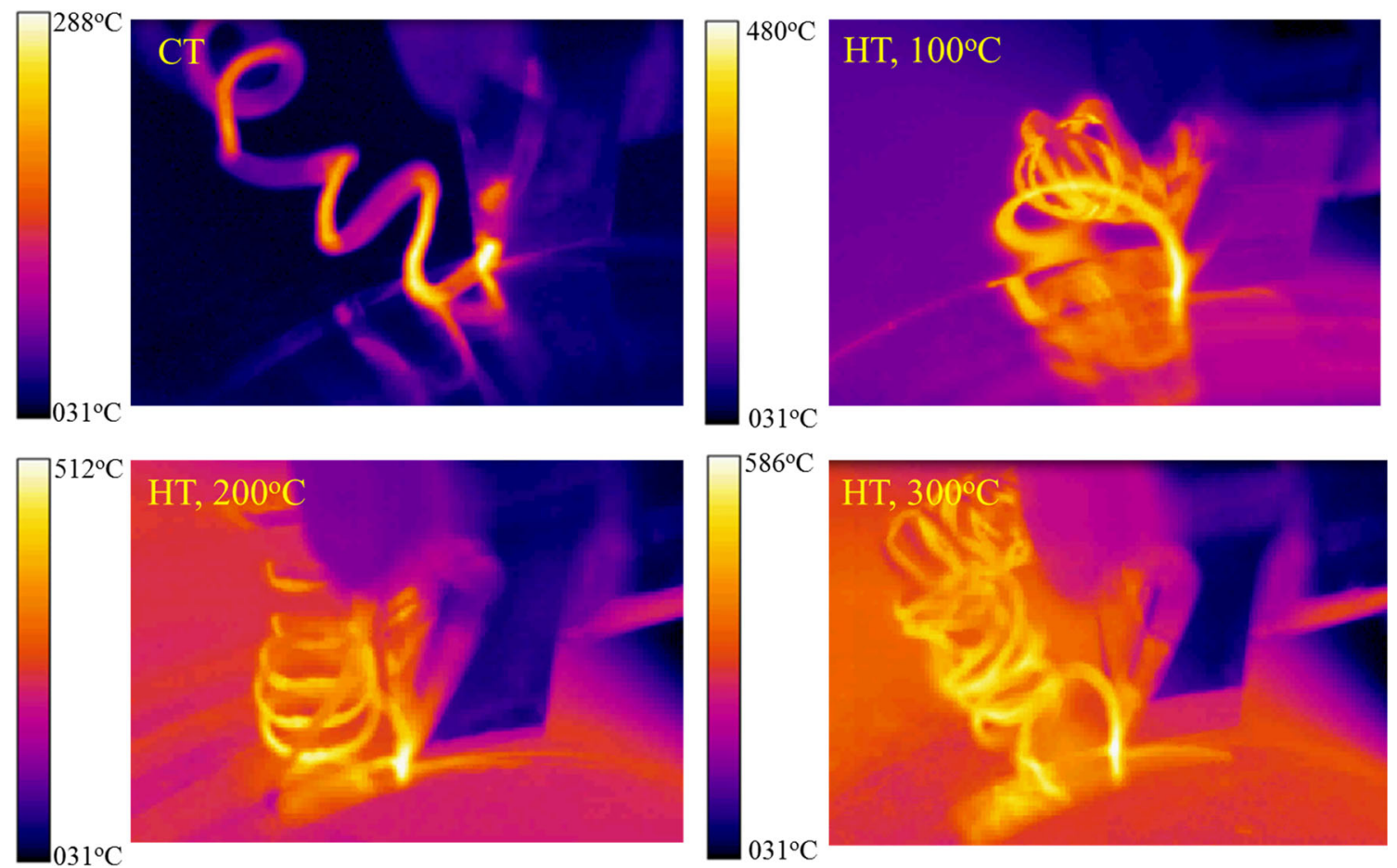

Fig. 6 Thermal analysis of the process zone in CT and HT $\left(V=10 \mathrm{~m} / \mathrm{min} ; a_{p}=0.3 \mathrm{~mm}\right)$ 
Fig. 7 Temperature levels and calculated plastic-heat generation

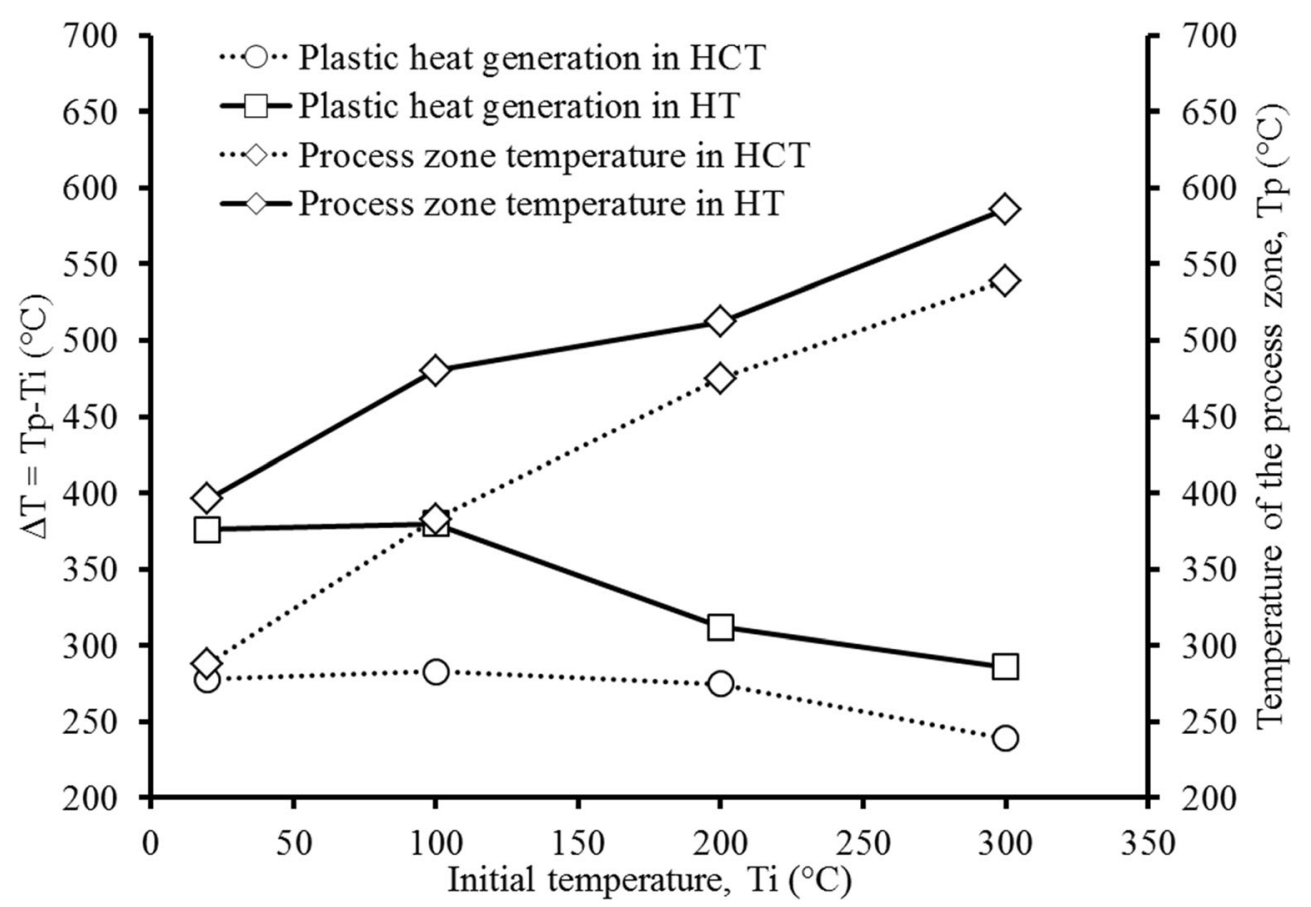

temperature [26]. The test was conducted for each set of cutting parameters and was lasted for about $75 \mathrm{~s}$ to measure the required output parameters. The machining conditions were established to the chosen magnitude in the first $20 \mathrm{~s}$, HCT for $20 \mathrm{~s}$, and followed by HT for approx. $30 \mathrm{~s}$ as shown in Fig. 2. Individual test was conducted 5 to 6 times to acquire realistic data.

During HT, random vibrations in the axial and radial direction having an amplitude of approx. 0.0001 and $0.0003 \mathrm{~mm}$, respectively, were observed, whereas in the velocity direction, a magnitude of $0.008 \mathrm{~mm}$ was recorded.

\subsection{Process zone temperature in $\mathrm{CT}, \mathrm{HCT}$, and $\mathrm{HT}$}

In CT, HCT, and HT, the FLIR ThermaCAM SC-3000 system was operated for thermal analysis of the process zone. The movement of the heater was controlled manually in all tests for HCT and HT processes as suggested by the manufacturer to avoid thermal damage to the camera. The recorded quantities were studied using the Quick-view Software to analyze data as shown in Fig. 3.

\subsection{Surface, sub-surface tests}

The surface roughness of machined specimens was carried out using Zygo® newview-5000 interferometry equipment. The standard, arithmetic means surface roughness parameter $(R a)$ was measured using the machine perpendicular to the feed marks. Measurements of $R a$ were taken at various locations of the specimens and all tests were repeated five times to get a reasonable statistical data for $R a$.

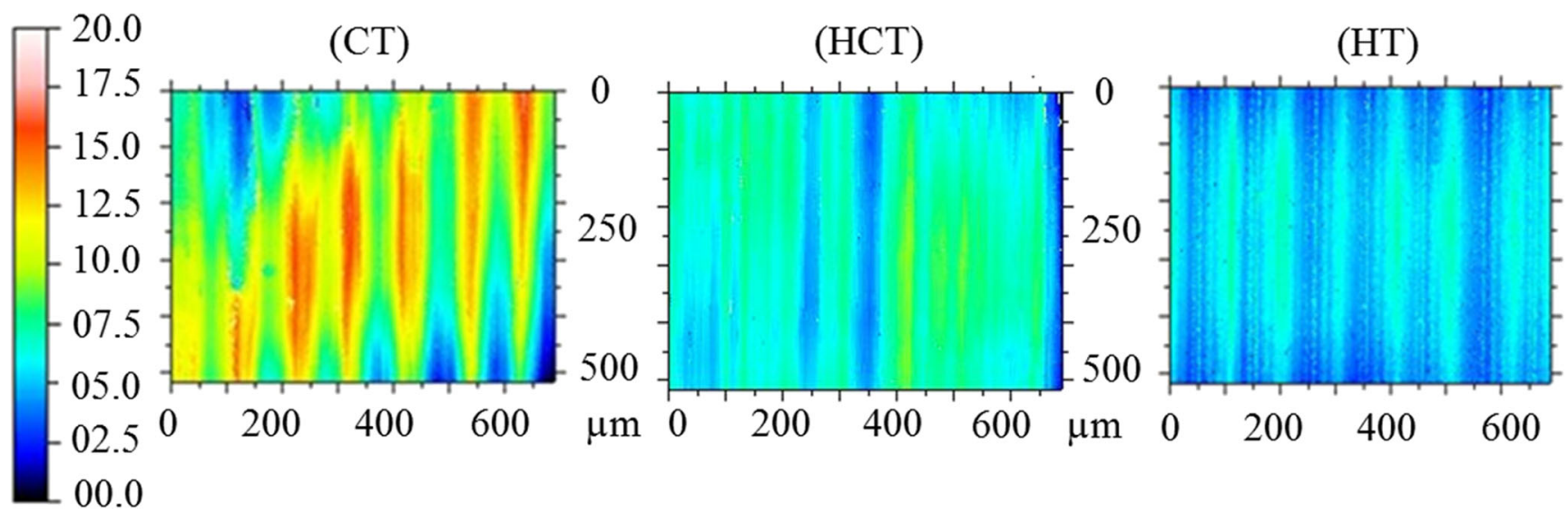

Fig. 8 2D field plots of surface texture at $V: 10 \mathrm{~m} / \mathrm{min}$ and $a_{p}: 0.3 \mathrm{~mm}$ 
Fig. 9 Surface roughness in HCT and $\mathrm{HT}$ at various temperatures

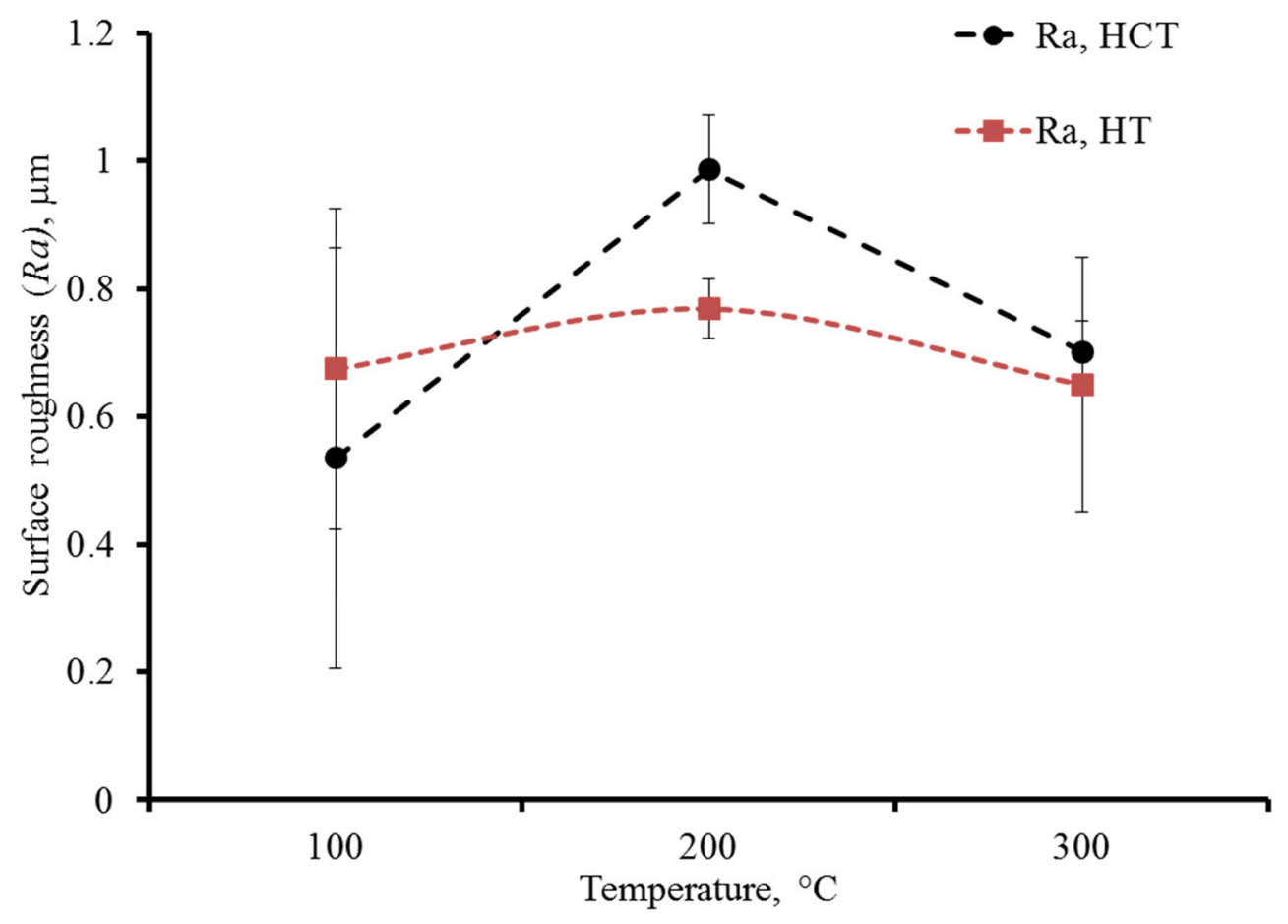

Similarly, titanium alloys are very responsive to metallurgical changes and oxidation, when exposed for longer period of time to high temperature (for more than $1 \mathrm{~h}$, approximately at $450{ }^{\circ} \mathrm{C}$ ) [26]. In the current study, all investigations were conducted in open air without any shielding. Supplementary, in CT and HT processes, several hundred degrees-centigrade raised in temperature was noted at the insert-workpiece interaction. Therefore, light microscopy followed by scanning electron microscopy (SEM) and microhardness testing of machined specimens were carried out using Nikon Optiphot, Carl Zeiss Leo 1530 VP electronic microscope and NanoTest NTX3, respectively, to observe the behavior of the material under study in CT, HCT, and HT. Material response and chip shapes were also investigated by analyzing chips produced in different turning process.

\section{Discussion on experimental results}

\subsection{Measured cutting forces}

The measured cutting forces for various depths of cuts $\left(a_{p}\right)$ in all experiments performed for $\mathrm{CT}, \mathrm{HCT}$, and $\mathrm{HT}$ are shown in

Fig. 10 LM of machined samples
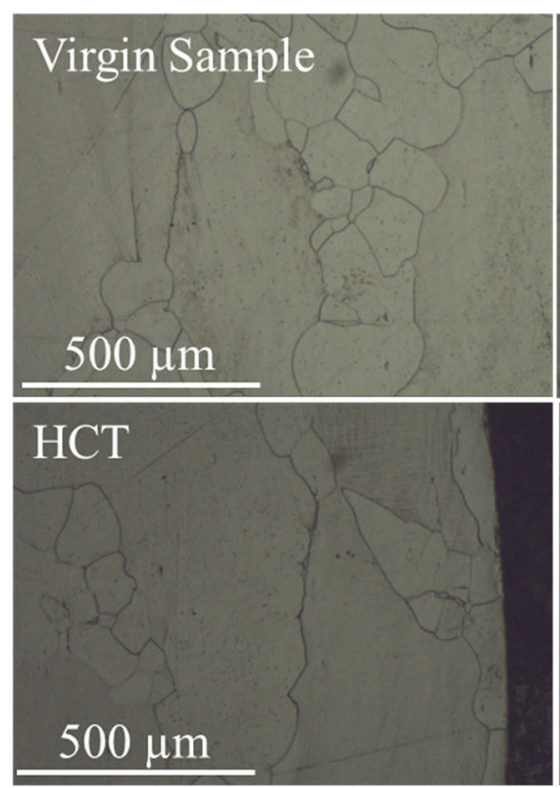

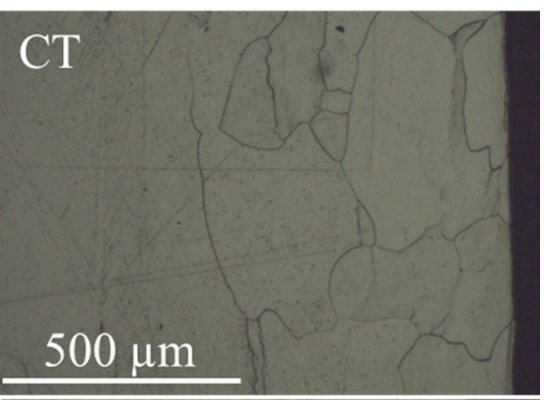

HT

$500 \mu \mathrm{m}$ 

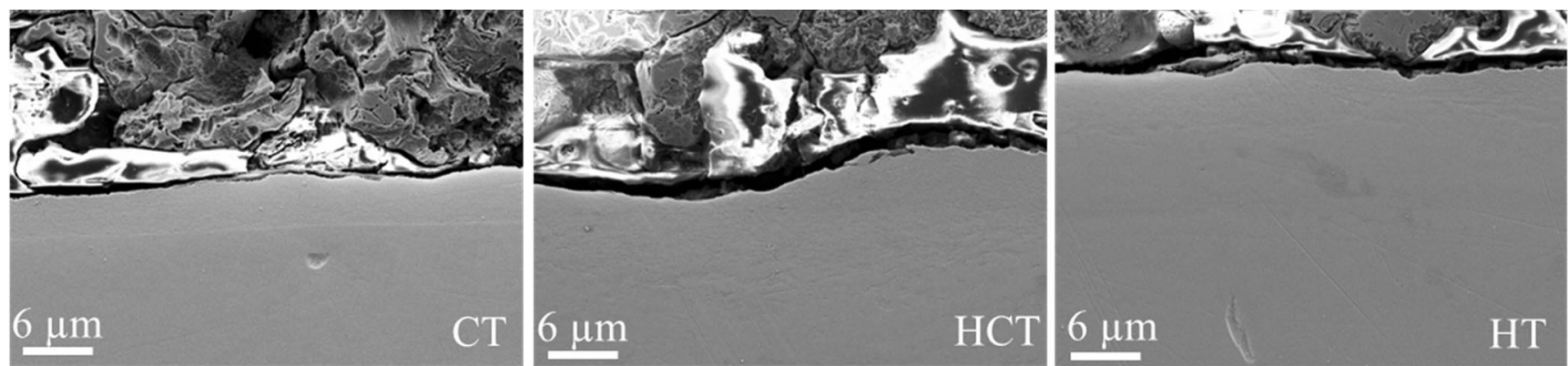

Fig. 11 SEM examination of samples

Fig. 4. A substantial decline in $F_{x}$ and $F_{y}$ was seen in presence of vibration and external heat in HT.

A gradual increase in the level of $F_{x}$ from 47 to $150 \mathrm{~N}$ was observed with a growth in $a_{p}$ from 0.1 to $0.5 \mathrm{~mm}$, respectively. Similarly, a rise in $F_{y}$ from 25 to $60 \mathrm{~N}$ was observed at the same depth of cuts.

Application of external heat to Ti-15333 and vibrations on the cutting insert yielded substantial reduction in $F_{x}$. A noticeable drop of 8 and $79.7 \%$ in $F_{x}$ was achieved at $100{ }^{\circ} \mathrm{C}$ and $a_{p}=0.3 \mathrm{~mm}$ in HCT and HT, respectively (Table 3 ). Similarly, further decline of 3 and $5 \%$ was measured at $200{ }^{\circ} \mathrm{C}$ in both HCT and HT, respectively. The drop in HT and HCT reached to 83.2 and $20 \%$, respectively, as compared to CT.

Similarly, a visible reduction in the level of $F_{y}$ was recorded in HT process (see Table 3). A reduction of 80 and $8 \%$ in $F_{y}$ was witnessed in HT and HCT, respectively, for $100{ }^{\circ} \mathrm{C}$ preheated condition. An additional increase of $100{ }^{\circ} \mathrm{C}$ in workpiece temperature resulted in a decline of 9.5 and $11 \%$ in HCT and HT, respectively. Also, the fall in $F_{y}$ at $300{ }^{\circ} \mathrm{C}$ is reached to 23 and $84 \%$ in $\mathrm{HCT}$ and $\mathrm{HT}$, respectively.

The assessment of HT with CT resulted in a noteworthy decline in measured cutting forces. At a depth of cut of $0.1 \mathrm{~mm}$, the reduction in $F_{x}$ and $F_{y}$ is approx. $95 \%$ in HT. The drop in $F_{x}$ and $F_{y}$ declines with growth in the level of $a_{p}$, and eventually, a steady reduction of $81-85 \%$ is achieved in HT above $0.2 \mathrm{~mm}$ depth of cuts and at $300{ }^{\circ} \mathrm{C}$ preheated condition. The decline in $F_{x}$ and $F_{y}$ was primarily credited to the drop in strength of Ti-15333 at higher temperatures [27]. Hence, the material removal rate (MRR) in HT is on the upper hand with comparison to CT for the same level of $F_{x}$ and $F_{y}$ on tool. As $F_{x}$ on the tool was $46 \mathrm{~N}$ at $0.1 \mathrm{~mm}$ depth of cut, whereas at $a_{p}=0.5 \mathrm{~mm}, 27 \mathrm{~N}$ in HT was measured. Therefore, MRR increased substantially in HT. The measured results demonstrated that application of both heat and vibrations in machining of Ti-15333 enhanced its machinability and resulting, a significant fall in the level of $F_{x}$ and $F_{y}$ as well as increased considerably its MRR.

\subsection{Thermal analysis}

The scattering of the process zone temperature in studied processes is presented in Fig. 5. An upper level of process zone temperature was noted in HT as compared to $\mathrm{CT}$ due to external heat supplied to the Ti-15333 and vibration applied on the cutting insert. The process zone temperature in HCT (at $300{ }^{\circ} \mathrm{C}$ ) was nearly $250{ }^{\circ} \mathrm{C}$ higher than CT. The increase in temperature is steady with the extent of heat supplied to Ti15333.

Also, the chip temperature increased, significantly, with ultrasonic vibrations and external heat in HT as presented in Fig. 6 . The potential reason is the added influence, associated to indulgence of vibration-energy and external heat [22]. An approximately $300{ }^{\circ} \mathrm{C}$ higher temperature was recorded in HT when linked to that measured in $\mathrm{CT}$ at $300^{\circ} \mathrm{C}$ preheated condition. Similarly, at 100 and $200{ }^{\circ} \mathrm{C}$ preheated conditions, the process zone temperatures are 192 and $224^{\circ} \mathrm{C}$ higher than CT in HT, respectively.

The calculated decline in plastic-heat generation in HCT and $\mathrm{HT}$ is presented in Fig. 7. A gradual decline in plastic-heat generation was noted, decreasing the extent of energy
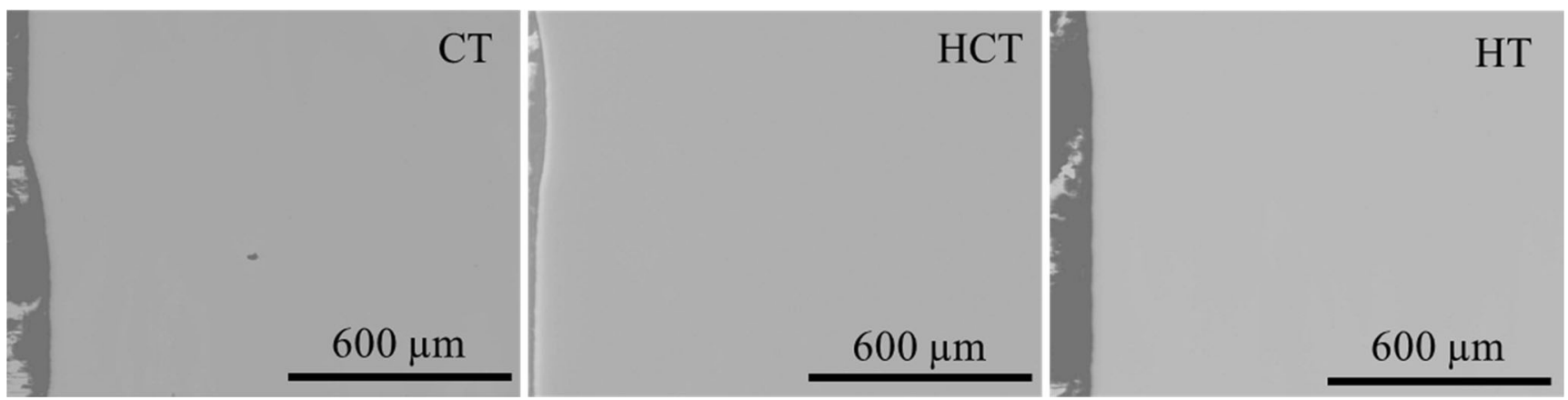

Fig. 12 Backscatter examination of samples 
necessary to eliminate the required quantity of material in HCT and HT.

During experimentation, the engagement zone of the workpiece-tool is not discernable to the IR system. Therefore, all measured temperature levels represent the chip temperatures in all studied processes. However, a good prediction of produced process zone temperature was accomplished for CT, HCT, and HT.

\subsection{Surface and sub-surface analysis}

In HT, excess of $50 \%$ improvement in surface topography parameters was found when results are compared to that of CT. In a 2D field plots, texture of machined surfaces in CT, HCT, and HT is shown in Fig. 8. Notably, periodicity is seen for CT machined surface, but for HT, it is somewhat shortened. The attained surface feature in both HCT and HT was statistically identical.

The $R_{a}$ value of $1.73 \mu \mathrm{m}$ was observed in $\mathrm{CT}$ of Ti15333 at $10 \mathrm{~m} / \mathrm{min}$ cutting speed and $a_{p}=0.3 \mathrm{~mm}$. A significant drop in $R_{a}$ was measured in HT and HCT, when compared to the results achieved in CT as shown in Fig. 9. A 62 and 59\% drop in the $R_{a}$ level was noted in HT and HCT, respectively. Application of external heat made Ti-15333 softer, enabling easier chip-flow to the insert cutting edge, yielding enhancement in the surface finish of the processed alloy. Similarly, the vibration imposed on the cutting insert further polishes the machined surface.

Additionally, the effect of heat and vibration on Ti-15333 in HCT and HT was investigated through light microscopy (LM). The results showed no marks of oxidation and metallurgical variations with temperature and heat as shown in Fig. 10. The observed grain size in studied alloy is not uniform and was varying all over the specimen as reported [26]. A

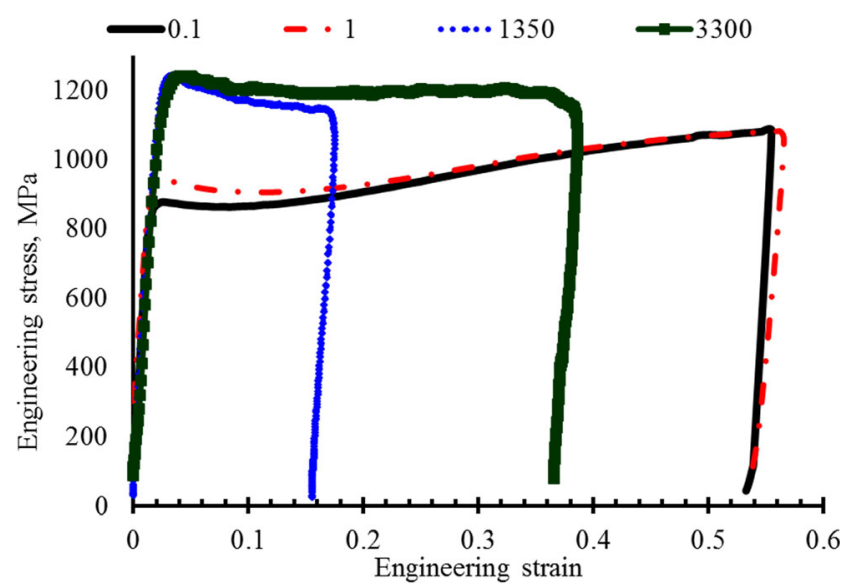

Fig. 14 Split-Hopkinson test results at room temperature and different strain rates [31]

needle shape precipitate was witnessed in Ti-15333 chips, exposed to above $450{ }^{\circ} \mathrm{C}$ temperature for more than $1 \mathrm{~h}$ [26]. In the current study, a concentrated temperature of $586{ }^{\circ} \mathrm{C}$ was measured in HT, and to nullify the formation of alpha precipitate $(\alpha-\mathrm{Ti})$ during the cutting operation, the collected samples were analyzed using scanning electron microscopy (SEM). In the analysis, a vastly deformed zone of nearly $3-5 \mu \mathrm{m}$ was seen near the cut surface as shown in Fig. 11. The region was etched differently; however, no confirmation of the $\alpha$-Ti was noted in SEM, and therefore, the backscatter analysis was carried out to further investigate the observed deformed layer. In the backscatter investigation, the existence of $\alpha$-Ti was excluded, as shown in Fig. 12. Though it is established that the differently imprinted zone in HT, HCT, and $\mathrm{CT}$ is the deformed material witnessed in chip formation examination of Ti-15333 [26], hence, HT established an extensive drop in $F_{x}$ and $F_{y}$ as well as noticeable enhancement in surface quality [28] with no sub-surface changes in the studied alloy.
Fig. 13 FE model with insert geometry

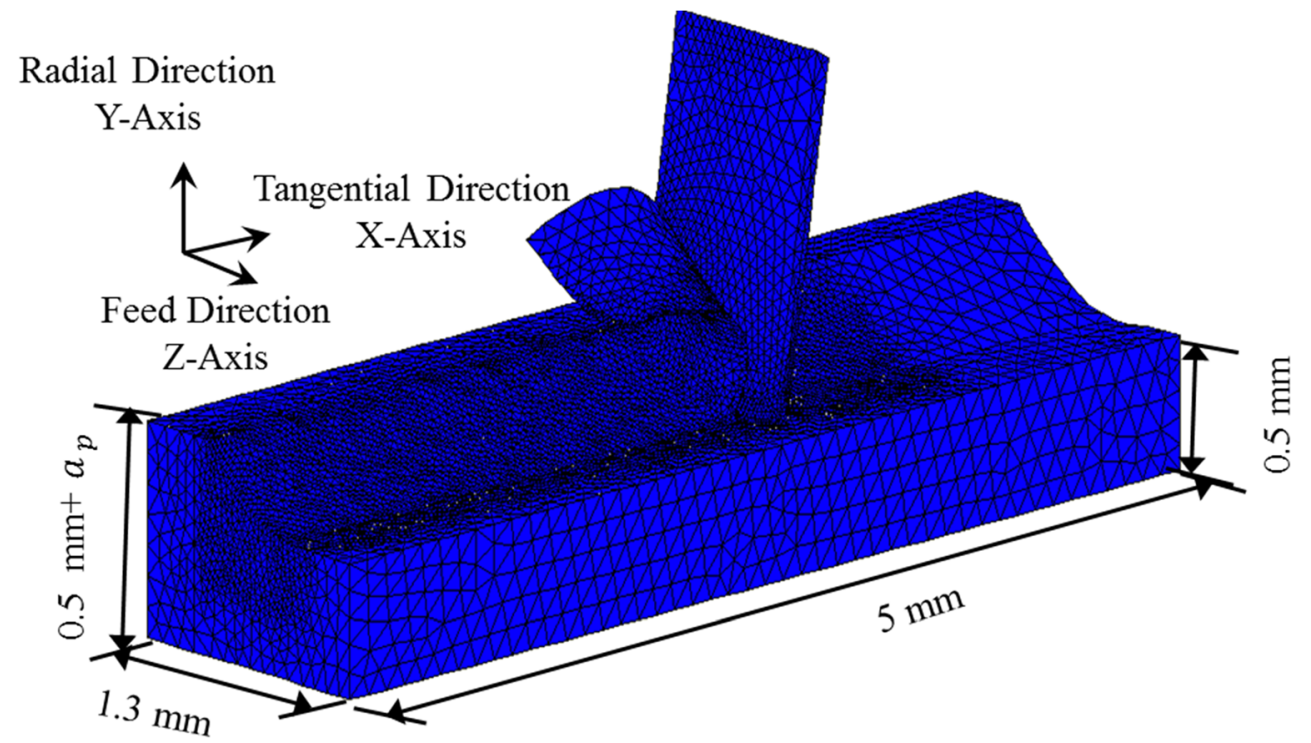




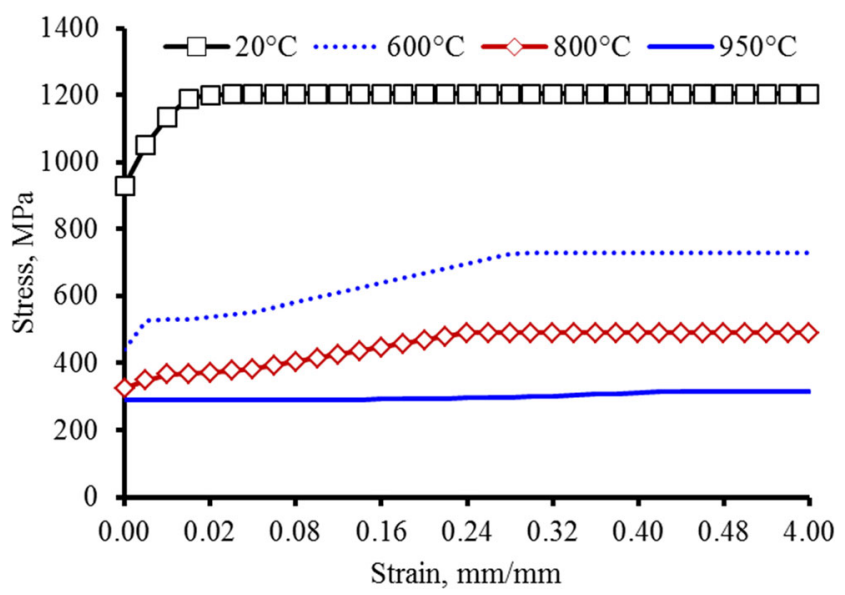

Fig. 15 Ti-15333 flow stresses at strain rate of $3300 / \mathrm{s}$ and various temperature [31]

\section{FE modeling of CT and HT processes}

A commercial code MSC Marc Mentat was used to establish implicit FE model for HT and CT [29]. The models were based on Lagrangian procedure which offers a transient analysis and incorporating the frictional interaction between the workpiece and insert.

\subsection{Model description and features}

In machining operations, the process zone temperature increases significantly and considerably effect thermal and mechanical properties of materials owing to non-linear material response at high temperatures. The established model incorporates non-linear material responses with temperature growth.

The true edge geometry of the DNMG-080615 tool insert is modeled as rigid body in the current models to certify all three components of forces in HT and CT having heat transfer capabilities. Four-noded tetrahedron elements were

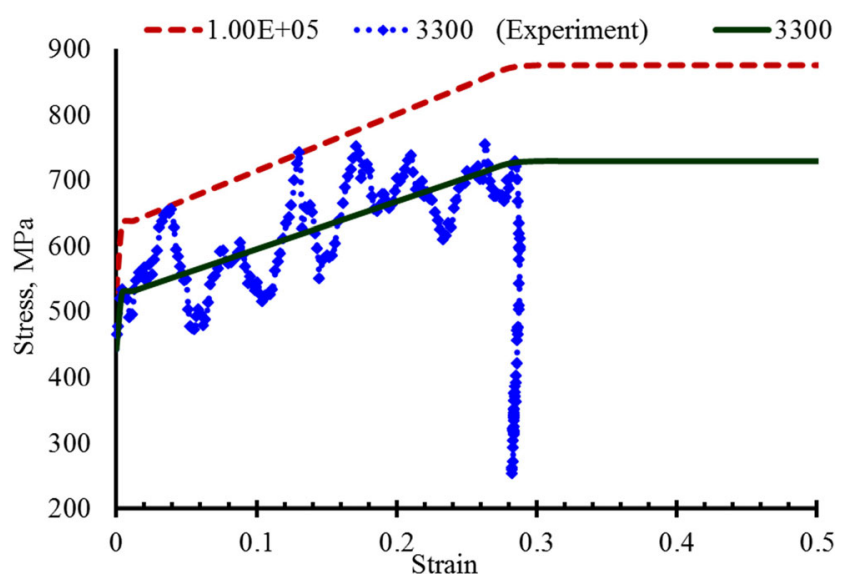

Fig. 16 Modified material response used in FE simulation at $600{ }^{\circ} \mathrm{C}$ [31]

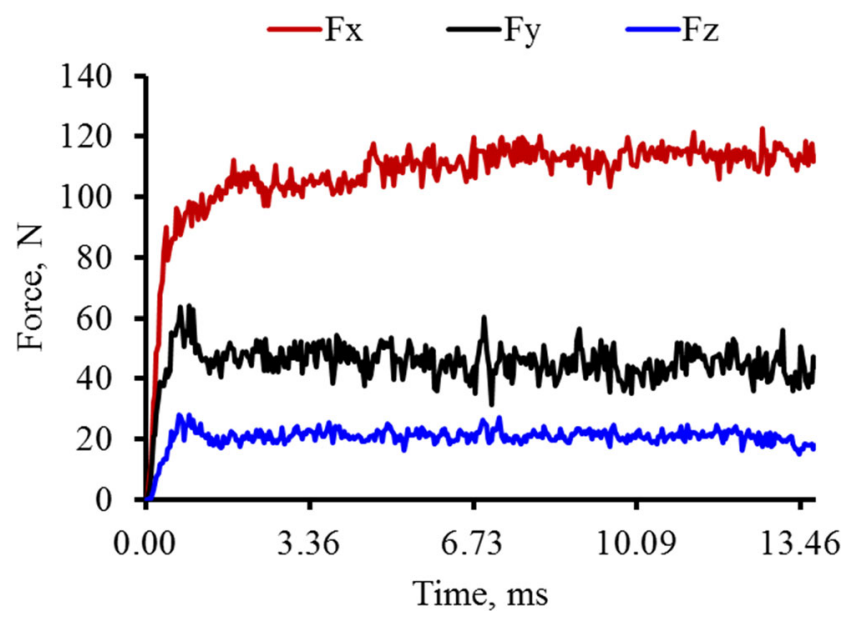

Fig. $17 \mathrm{FE}$ results of forces in $\mathrm{CT}\left(V=10 \mathrm{~m} / \mathrm{min} ; f_{r}=0.1 \mathrm{~mm} / \mathrm{rev} ; a_{p}=\right.$ $0.3 \mathrm{~mm}$ )

used to discretize the insert in to 8000 elements. Vibration of frequency $(f)$ and amplitude $(a)$ was applied on the insert in the X-direction in HT as shown in Fig. 13. In addition, to the study of one-dimensional vibration modes, elliptical vibrations were also imposed on the insert to study its effect on cutting forces. The following equations of motion were used to define vibration superimposed on the cutting tool:

$x(t)=a \cos (2 \pi f t)$

$y(t)=b \cos (2 \pi f t+\varphi)$

Here, $a$ is the amplitudes in tangential direction while $b$ in radial direction; $f$ is the frequency, $\varphi$ phase angle, and $t$ is the time.

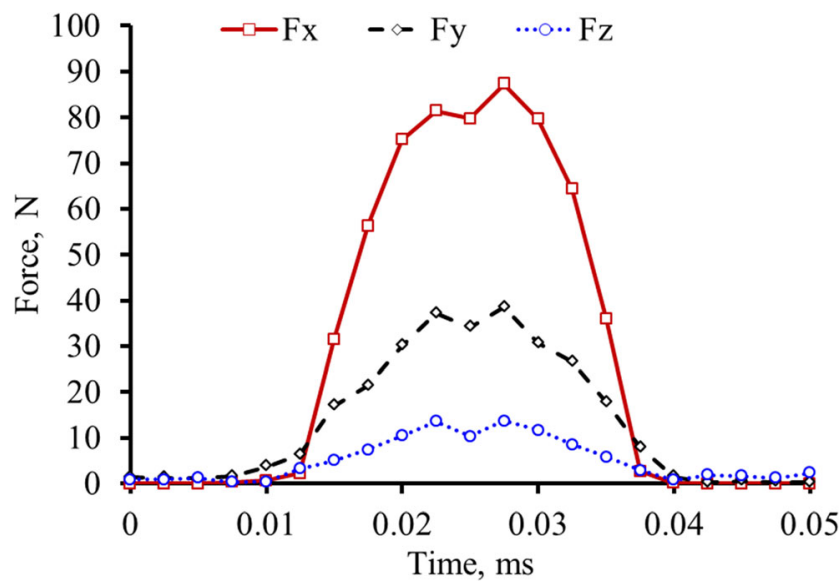

Fig. 18 Simulated forces in HT in one complete vibration cycle $(V=$ $10 \mathrm{~m} / \mathrm{min} ; f_{r}=0.1 \mathrm{~mm} / \mathrm{rev} ; a_{p}=0.3 \mathrm{~mm} ; T=300{ }^{\circ} \mathrm{C}$ ) 
Fig. 19 Experimental and numerical result comparison

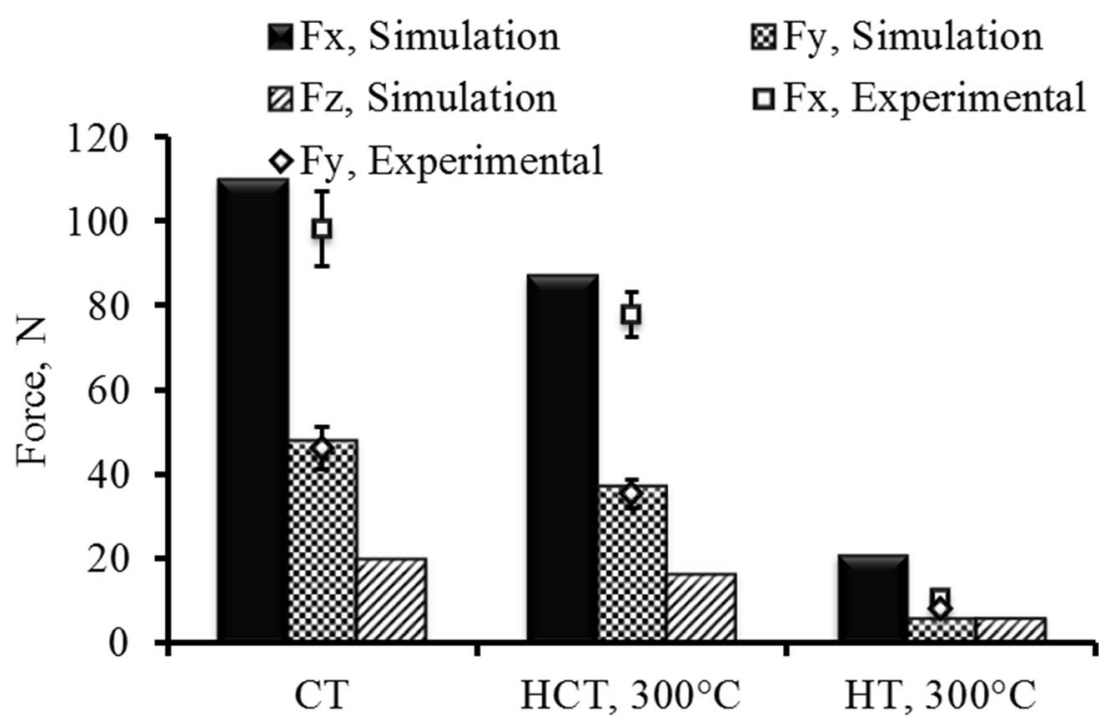

For elliptical vibrations, amplitude of 8 and $4 \mu \mathrm{m}$ was applied on the insert in tangential and in radial direction, respectively.

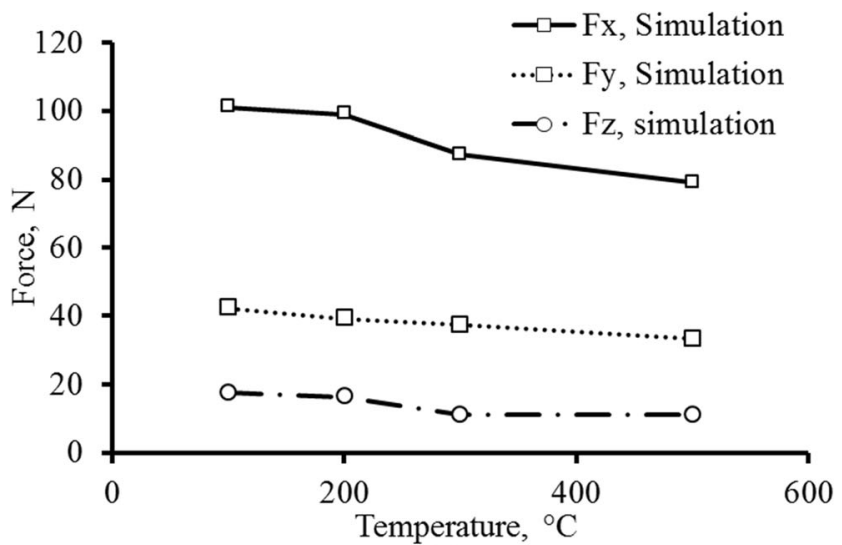

(a)

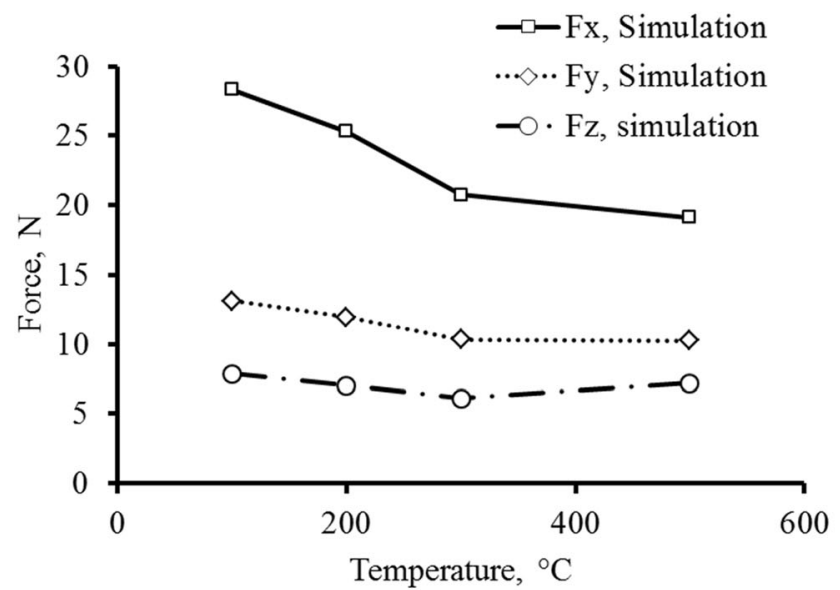

(b)

Fig. 20 The levels of $F_{x}, F_{y}$ and $F_{z}$ a HCT and b HUAT $\left(a_{p}=0.3 \mathrm{~mm}\right.$, $V=10 \mathrm{~m} / \mathrm{min}$, and $f_{\mathrm{r}}=0.1 \mathrm{~mm} / \mathrm{rev}$ )
A workpiece having a height of $0.5 \mathrm{~mm}+a_{p}$, width of $1.3 \mathrm{~mm}$, and length of $5 \mathrm{~mm}$ is modeled in the FE model. The cutting velocity was assigned to the workpiece (see Fig. 13). Firstly, eight-noded hexahedral elements with $0.05 \mathrm{~mm}$ of length were used to mesh the workpiece. To attain local mesh refinement, the global remeshing was defined to regions close to the cutting edge resulting elements having length equal to $0.0125 \mathrm{~mm}$ after mesh convergence tests. The assigned mesh was finalized after mesh convergence study.

\subsection{Material model}

A linear piecewise material model is implemented to include the flow stress behavior of studied alloy at high strain rates and temperatures. For Ti-15333 [30], Split-Hopkinson (SH) tests were conducted at Tampere University of Technology (TUT),

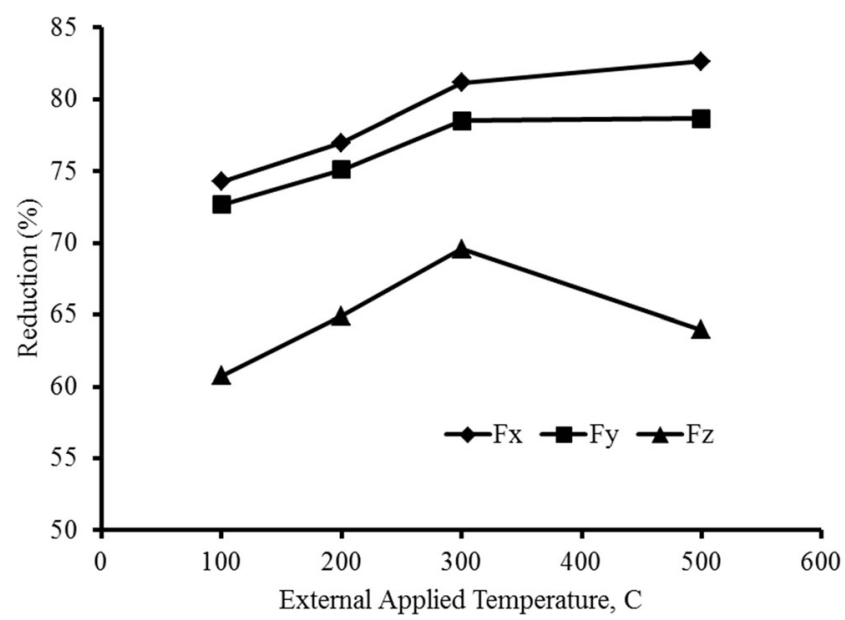

Fig. 21 Reduction in forces (as compared to CT) at studied temperature levels in HT 


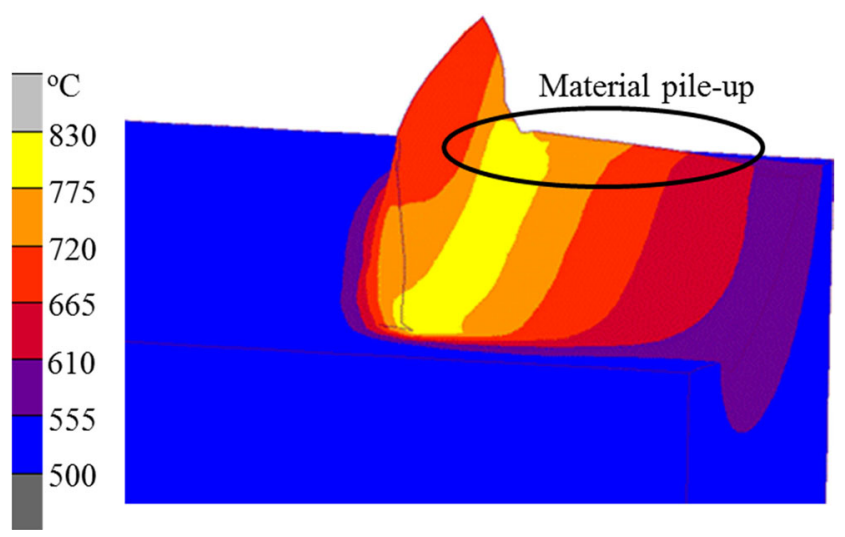

Fig. 22 Accumulation of materials in $\mathrm{HT}$ at $500{ }^{\circ} \mathrm{C}$ in feed direction

Finland. In the acquired results at different strain rates, temperatures are presented in Figs. 14 and 15.

The main limitation of the SH setup at TUT is its functionality at strain rate of $3300 \mathrm{~s}^{-1}$ where as in machining processes, it extended to $10^{5} \mathrm{~s}^{-1}[31,32]$. Therefore, an interpolation method using FE simulations of SH tests was adopted to incorporate material response at $10^{5} \mathrm{~s}^{-1}$. Additional detail about the study can be found elsewhere [19] (Fig. 16).

Moreover, the curves used in material model were changed in a manner that the levels of stress for higher

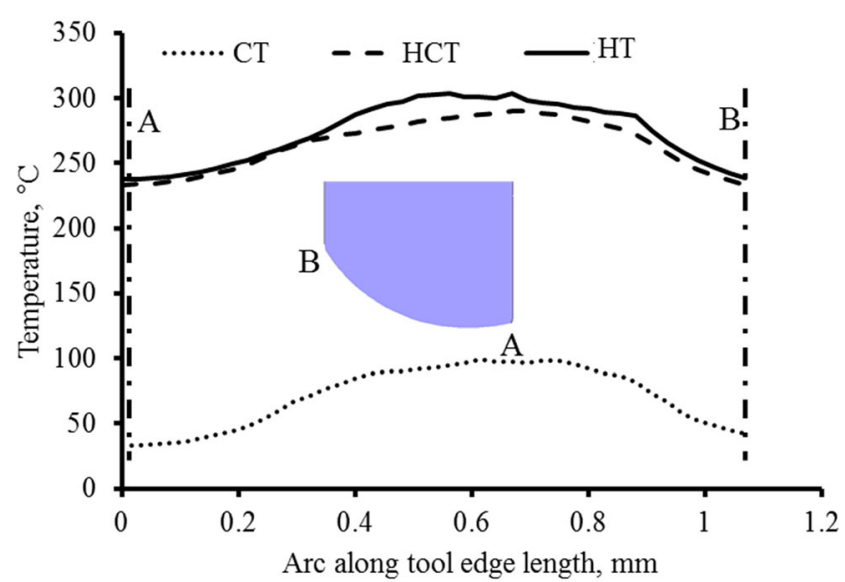

Fig. 24 Temperature spreading on rake face $\left(V=10 \mathrm{~m} / \mathrm{min} ; a_{p}=0.3 \mathrm{~mm}\right.$; $f_{\mathrm{r}}=0.1 \mathrm{~mm} / \mathrm{rev} ; T=300^{\circ} \mathrm{C}$ )

strain magnitudes are restricted by the ultimate tensile stress (UTS). The temperature and strain rate sensitive material model used in our FE simulations included of various stress-strain curves achieved from four different temperature levels $\left(20,600,800\right.$, and $\left.950{ }^{\circ} \mathrm{C}\right)$ and four strain rates $\left(0.1,1,3331\right.$, and $\left.10^{5} \mathrm{~s}^{-1}\right)$. All the data used in material model was fed to the software in tabulated form.
Fig. 23 Temperature spreading in $\mathrm{CT}$, HT, and HCT $(V=10 \mathrm{~m} / \mathrm{min}$; $a_{p}=0.3 \mathrm{~mm} ; f_{\mathrm{r}}=0.1 \mathrm{~mm} / \mathrm{rev} ; T=$ $300{ }^{\circ} \mathrm{C}$ )
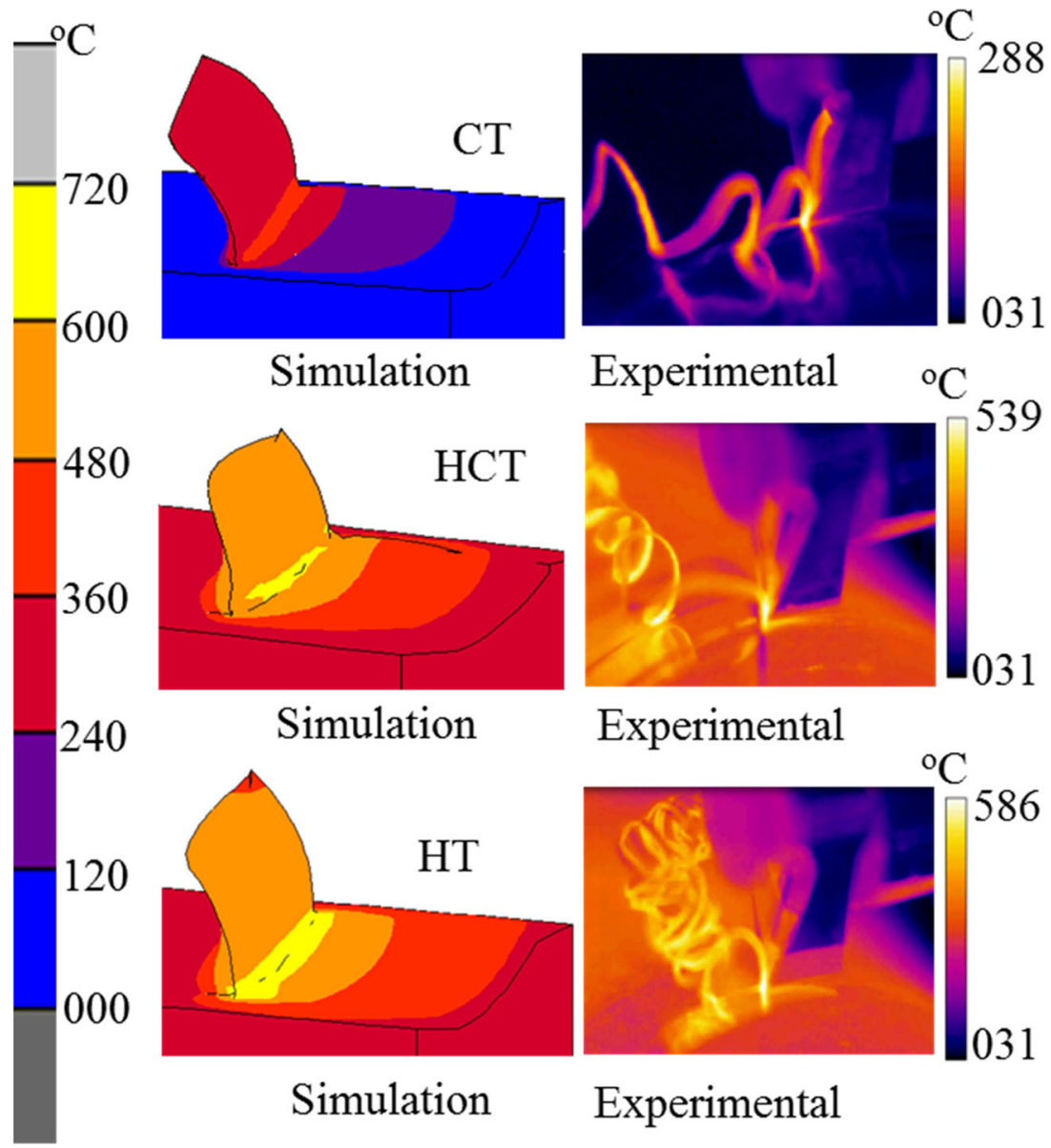

Simulation

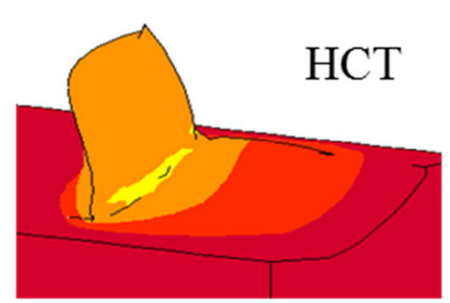

Simulation

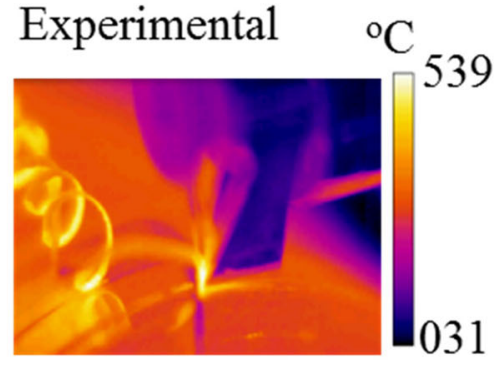

Experimental

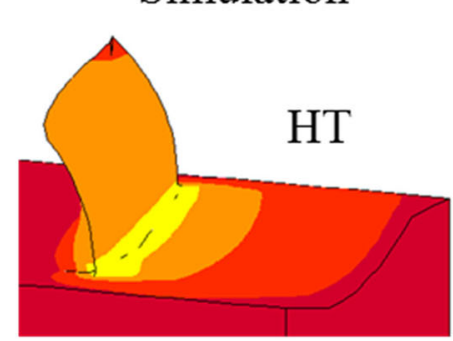

Simulation

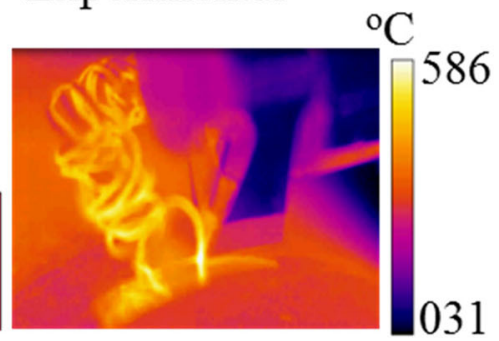

Experimental 
Fig. 25 Temperature plot on rake face

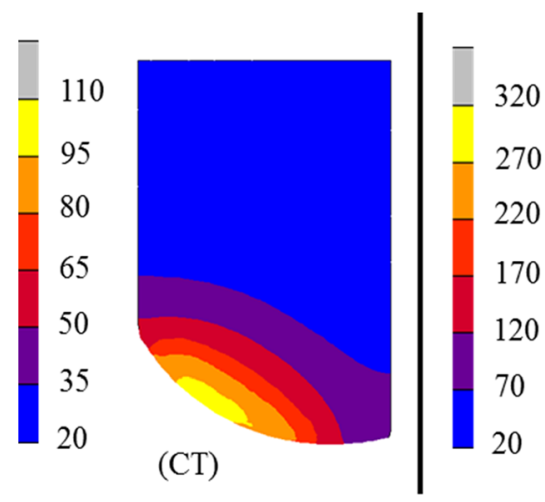

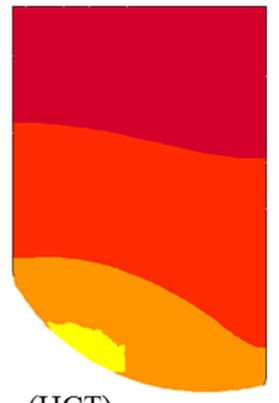

(HCT)

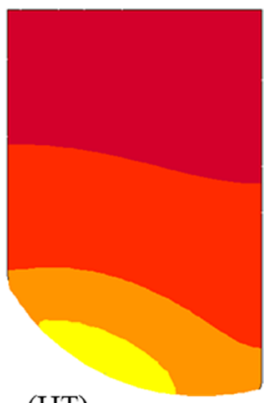

(HT)

\section{FE outcomes and discussion}

\subsection{Cutting force}

The developed oblique model was used to calculate $F_{x}, F_{y}$, and $F_{z}$ (axial component of force) in CT, HCT, and HT. The magnitude of $F_{x}$ was $110 \mathrm{~N}$ in $\mathrm{CT}$ as shown in Fig. 17. The levels of $F_{y}$ and $F_{z}$ were 48 and $20 \mathrm{~N}$, respectively, which were achieved through FE simulation. At the initial stage, the achieved levels of $F_{x}, F_{y}$, and $F_{z}$ on the insert were zero before contact. The extents of these forces swiftly increased with the tool-workpiece contact, and after a full engagement of the tool with the workpiece material, a steady-state magnitude of cutting forces was seen in CT. The small fluctuation in achieved forces is resulted by global-remeshing used for chip separation in the current simulation.

With a combined effect of vibration and external heat, a sizeable decline in forces is witnessed in HT. In the penetration stage of the insert in HT, the insert indented the workpiece and resulted a peak level of $F_{x}, F_{y}$, and $F_{z}$ at full penetration. The simulated peak force levels were lower in scale when matched with CT, but nearly identical to HCT. The cutting forces start to drop and eventually reached to zero at full retraction (Fig. 18).

A substantial decrease in $F_{x}$ of approximately $80.5 \%$ was achieved in HT. The average levels of $F_{z}$ and $F_{y}$ decline from 20 to $6 \mathrm{~N}$ and from 48 to $11 \mathrm{~N}$, respectively. Hence, application of vibration on insert and heat to the workpiece in HT decreases the forces considerably. On the contrary, the drop in
$F_{x}, F_{y}$, and $F_{z}$ was 20,22 , and $40 \%$, respectively, in HCT when compared to the results achieved in $\mathrm{CT}$ at room temperature. A good agreement between simulated and experimental results was attained with an average error up to $10 \%$ (Fig. 19).

In the earlier work of Muhammad et al. [19, 25], they demonstrated that application of vibration on the cutting insert resulted a decline of 75,67 , and $52 \%$ in $F_{x}, F_{y}$, and $F_{z}$, respectively. However, in the current work, it was concluded that addition of heat with vibration resulted an additional drop of 15,11 , and $16 \%$ in $F_{x}, F_{y}$, and $F_{z}$, respectively.

The model was used for various heat sources covering from 100 to $500{ }^{\circ} \mathrm{C}$ to analyze the cutting forces. A measured drop in $F_{x}, F_{y}$, and $F_{z}$ was noted with an increase in temperature in both HT and HCT (Fig. 20). A drop of 28 and $82 \%$ in $F_{x}$ was observed at $500{ }^{\circ} \mathrm{C}$ in $\mathrm{HCT}$ and $\mathrm{HT}$, respectively. Also, a decline of 28 and $78 \%$ in the $F_{y}$ and 44 and $63 \%$ in the $F_{z}$ was recorded in HCT and HT, respectively (Fig. 21).

From simulation results, some minor reduction in $F_{x}$ was achieved at $500{ }^{\circ} \mathrm{C}$, whereas the level of $F_{y}$ was the same and a slightly growth in $F_{z}$ was noted. The main cause is unnecessary thermal softening of simulated specimen as presented in Fig. 22. Hence, a recommended temperature for the studied alloy in $\mathrm{HT}$ is $300^{\circ} \mathrm{C}$.

\subsection{Thermal analysis}

The recorded process zone temperature in CT was relatively lower as compared to HT and HCT. The heat externally applied to Ti-15333 significantly increased the process zone

Fig. 26 Plastic-strain plots in a CT and $\mathbf{b}$ HT

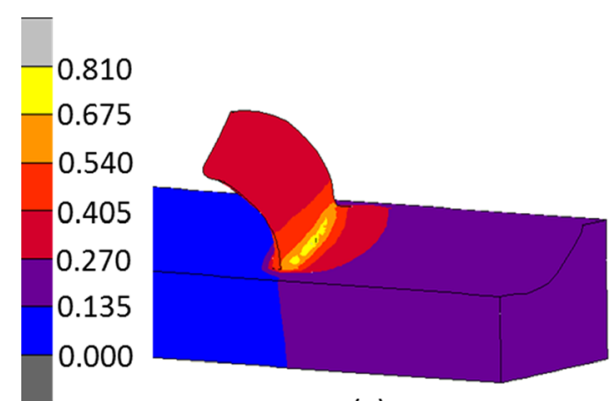

(a)

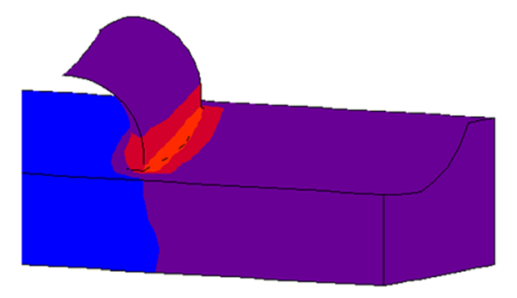

(b) 
temperature in HCT and HT. However, the level of temperature recorded from FE simulation in HT was higher than that in HCT at studied cutting conditions as presented in Fig. 23 and can be credited to the surplus energy (vibration) imposed on the insert. The developed FE models have an added advantage of revealing temperature profile in sections not observable to IR system in experimentations. In HT simulations, the calculated process zone temperature of $680{ }^{\circ} \mathrm{C}$ was recorded as compared to $600{ }^{\circ} \mathrm{C}$ in experimentation for the same cutting conditions.

The spreading of heat on the face of insert was plotted from FE simulation of CT, HT, and HCT. The highest temperature was identified at the rake face center (Fig. 24). The temperature spreading on the rake face of the insert changes with the

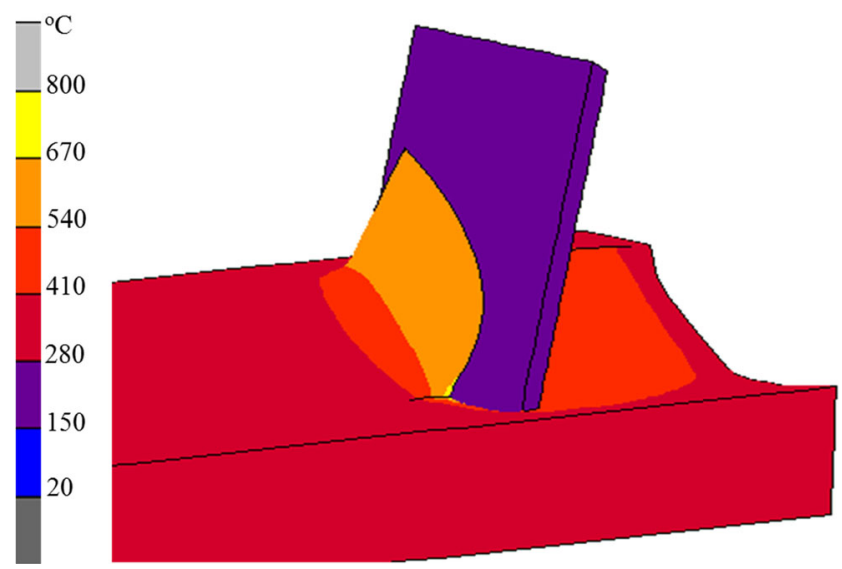

Fig. 28 Temperature spreading at $a_{p}=400 \mu \mathrm{m}$ at $t=3 \mathrm{~ms}$
Fig. 27 The level of $F_{x}, F_{y}$ and $F_{z}$ at studied depths of cuts $(V=$ $10 \mathrm{~m} / \mathrm{min} ; f_{\mathrm{r}}=0.1 \mathrm{~mm} / \mathrm{rev}$; and $T=300{ }^{\circ} \mathrm{C}$ )

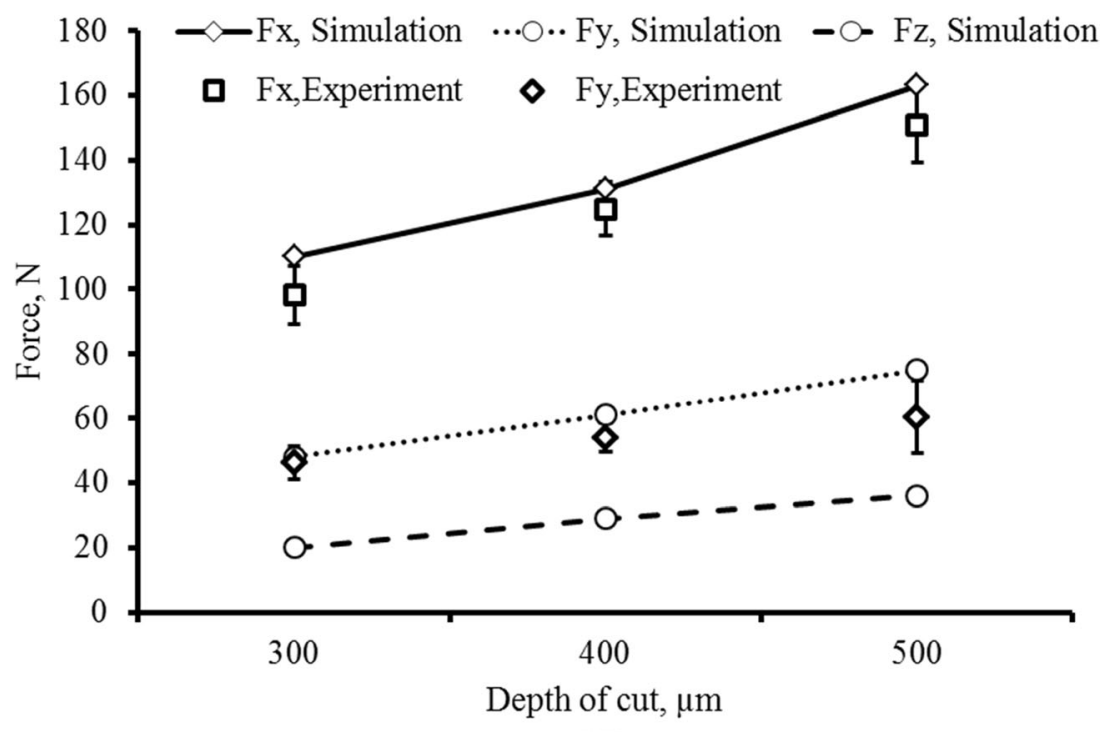

CT

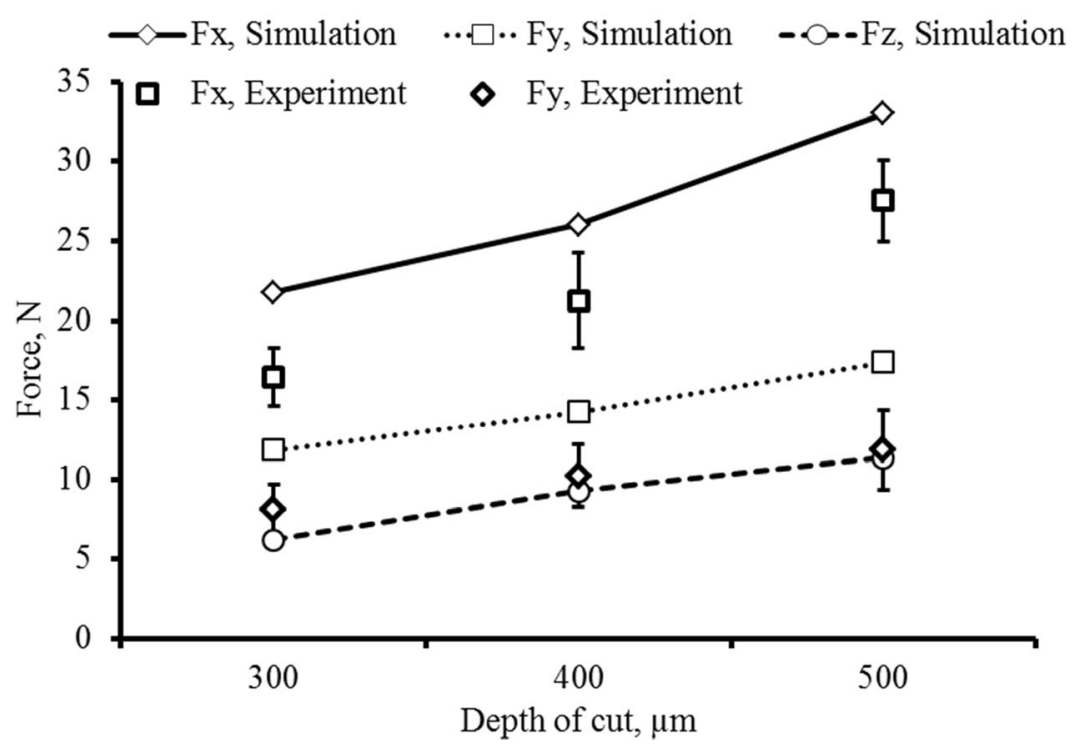

HT 
insert position in HT. A temperature of approx. 303 and $295{ }^{\circ} \mathrm{C}$ was noted at full penetration and retraction position (see Fig. 25). On the contrary, 100 and $290^{\circ} \mathrm{C}$ in CT and HCT, respectively, were measured. Similarly, plastic-strain was reduced by $33 \%$ in HT when compared to the level of plastic deformation observed in $\mathrm{CT}$ as presented in Fig. 26.

\subsection{Effect of depth of cut}

The FE simulation outcomes shown in Fig. 27 demonstrate the change in forces for tested depth of cuts. It is identified that $F_{x}$ is a principal component compared to $F_{z}$ and $F_{y}$ in both experimentations and simulations. A linear growth in the level of $F_{x}, F_{y}$ and $F_{z}$ was noted with rise in the depth of cut. A worthy agreement was accomplished in experimental and

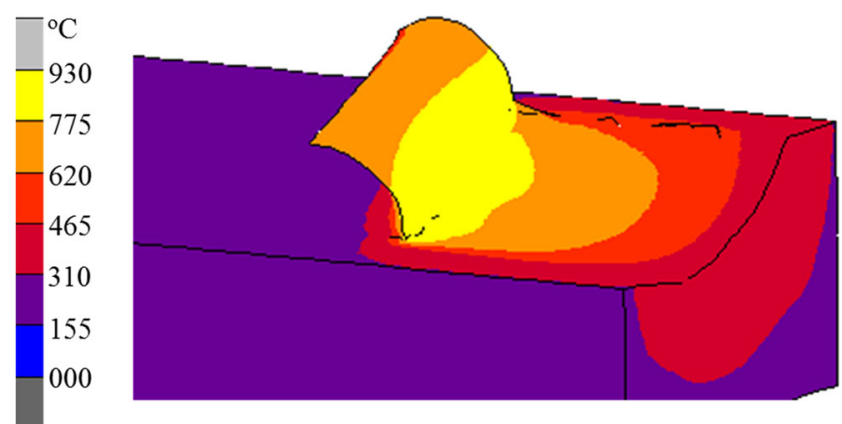

Fig. 30 Process zone temperature in HT $(70 \mathrm{~m} / \mathrm{min})$ at $t=1 \mathrm{~ms}$

simulated results as presented in Fig. 27. A drop of approximately $80.5,76.2$, and $68.3 \%$ in $F_{x}, F_{y}$ and $F_{z}$ was detected in $\mathrm{HT}$ at tested conditions.
Fig. 29 Levels of $F_{x}, F_{y}$, and $F_{z}$ : a CT and HCT, b HT
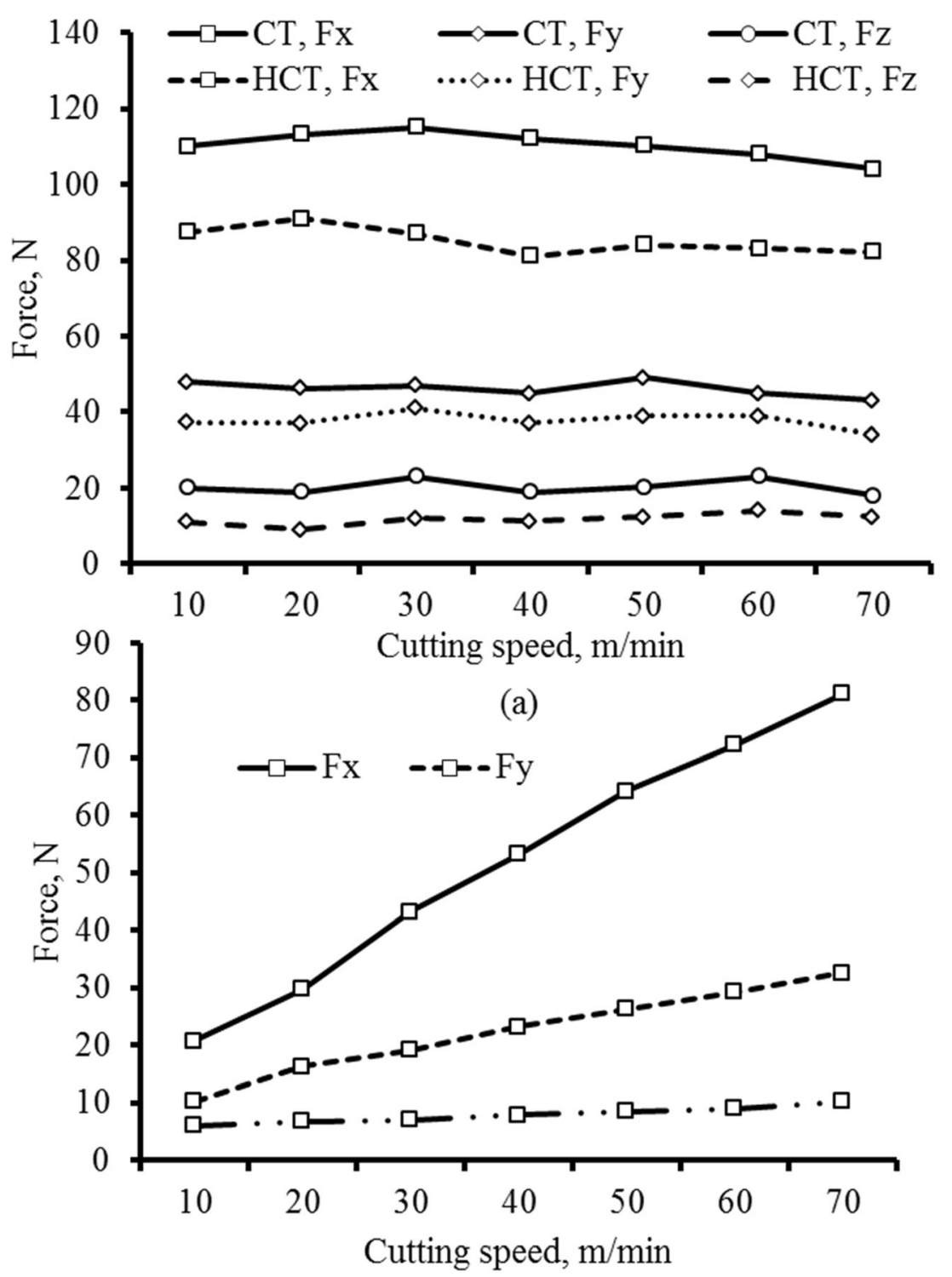

(b) 
Equally, process zone temperature was also analyzed and a growth in temperature at upper depth of cuts was observed due to high materials removed from the workpiece. Figure 28 presents a temperature spreading in HT at $400 \mu \mathrm{m}$ depth of cut.

\subsection{Effect of cutting speed}

Several speeds are used in the FE simulations of CT, HCT, and HT, and the established results are listed in Fig. 29. Nearly persistent levels of $F_{x}, F_{y}$, and $F_{z}$ were detected at tested speeds in HCT and CT. Conversely, the extent of average forces enlarged in HT with higher speeds and, ultimately, the decline in $F_{x}, F_{y}$, and $F_{z}$ disappeared above $70 \mathrm{~m} / \mathrm{min}$. The workpiece velocity at tested higher speed excludes separation among workpiece and insert resulted zero drop in forces. The decline in forces beyond the critical speed of $60 \mathrm{~m} / \mathrm{min}$ is credited to thermal softening triggered by vibrations and heat whereas the external heat resulted a discount of $21 \%$ in forces in HCT. The developed model showed same behavior for $F_{y}$ and $F_{z}$ in HT, as expected.

The influence of speed on the generated heat in HT is also examined. A growth in temperature is attained with the rise of speed, as expected (see Fig. 30).

\subsection{Effect of feed rate}

The obtained FE results of forces at studied feed rates are offered in Fig. 31. A linear growth in all force components was perceived with an increase in feed rate in studied machining processes. The volume of machined materials intensified
Fig. 31 Influence of feed rate on $F_{x}, F_{y}$ and $F_{z}$ in a CT and $\mathbf{b} \mathrm{HT}$
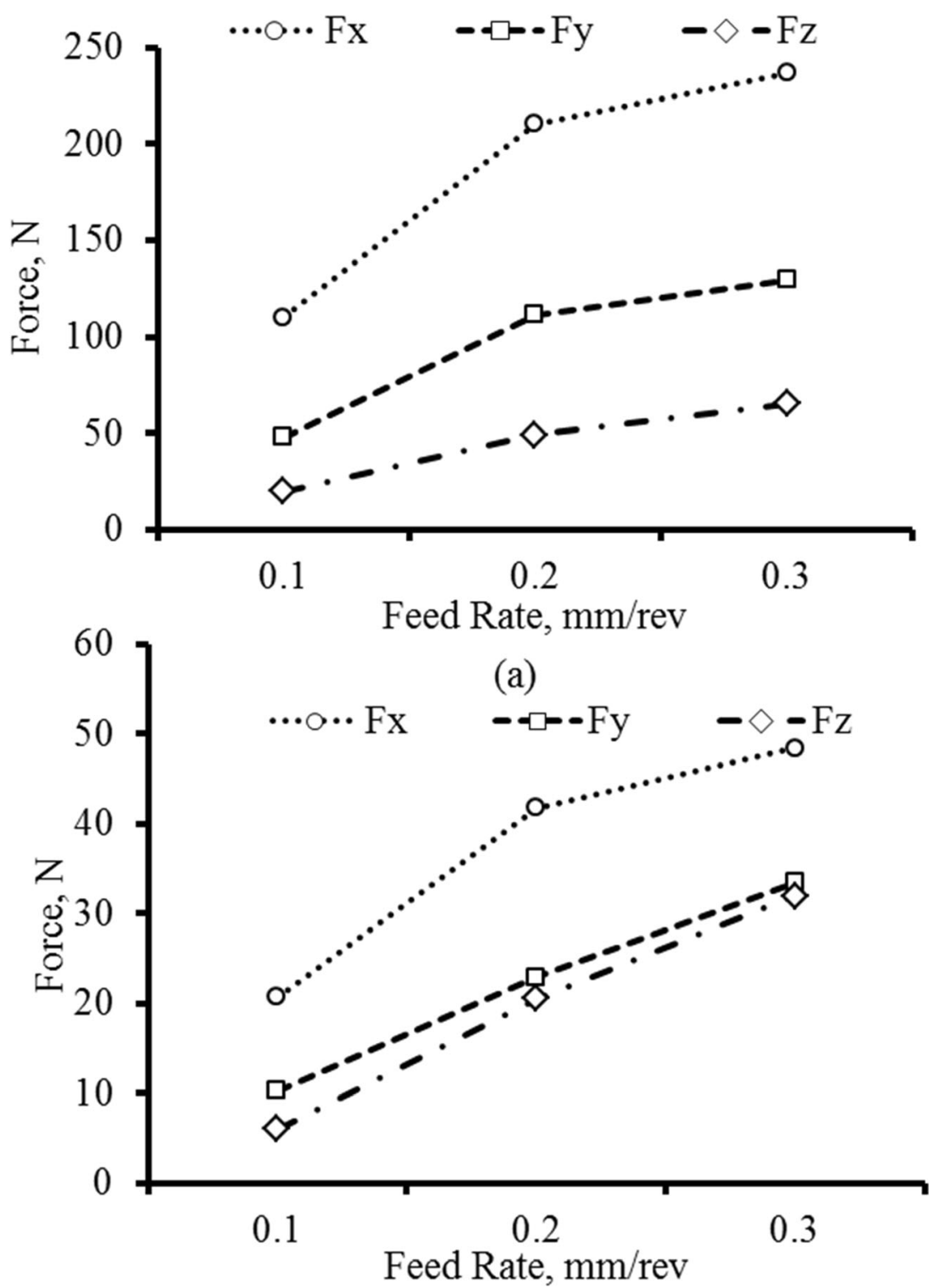

(b) 
at higher feed rate as expected, ensuing higher level of $F_{x}, F_{y}$, and $F_{z}$. However, the results demonstrated that the level of forces in HT is significantly lower even at higher feed rate when compared to CT. A decline of 74 to $80 \%$ was detected in $F_{x}$ and $F_{y}$ at higher feed rates. But the drop in the $F_{z}$ contracted, and 58 and $50 \%$ drop was seen at 0.2 and $0.3 \mathrm{~mm} / \mathrm{rev}$, respectively, due to shorter separation of insert in vibration. Hence, HT is also a good alternative at higher feed rates and depth of cuts, with an improvement in surface roughness and substantial decline in the cutting forces [28]. Equally, a growth in temperature was noted with feed rate in all studied processes, as expected.

The established FE model was also used for the study of forces using a range of insert edge radiuses ( 0 to $100 \mu \mathrm{m})$. The obtained results demonstrated a prime dependency of $F_{y}$ on it.
A sharp cutting edge resulted a minimum forces in all studied machining processes as shown in Fig. 32. A linear growth was detected above $25 \mu \mathrm{m}$ tool edge radius in forces for all studied machining processes. Yet, the tool edge radius had a prevailing importance on $F_{y}$ compared to $F_{x}$ and $F_{z}$ in both CT and HT.

\subsection{Stress analysis}

The obtained stress results revealed the same levels in HCT and HT at full penetration for the same cutting condition. The tool-workpiece contact can be categorized in four phases in HT namely: (a) approach phase, the insert travels toward the workpiece; (b) engagement phase, the insert enters into the workpiece material; (c) disengagement phase, the insert
Fig. 32 Cutting forces at studied cutting-edge radiuses of insert: a CT and $\mathbf{b}$ HT $(V=10 \mathrm{~m} / \mathrm{min} ; T=$ $300{ }^{\circ} \mathrm{C} ; f_{\mathrm{r}}=0.1 \mathrm{~mm} / \mathrm{rev}$ and $\alpha=$ $0^{\circ}$ )

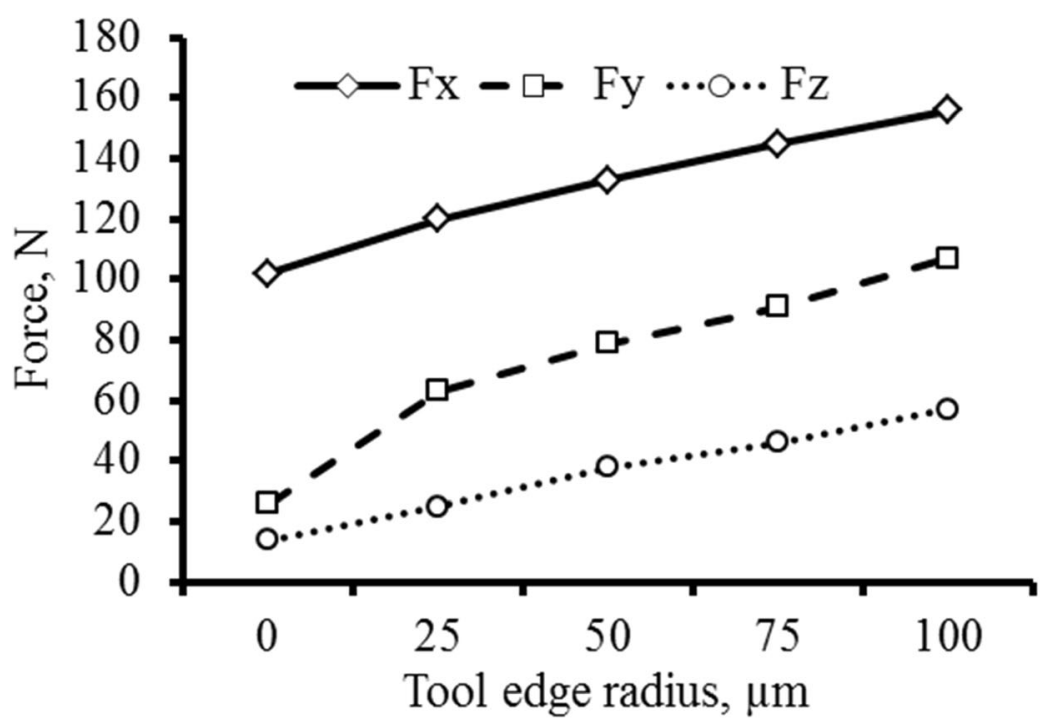

(a)

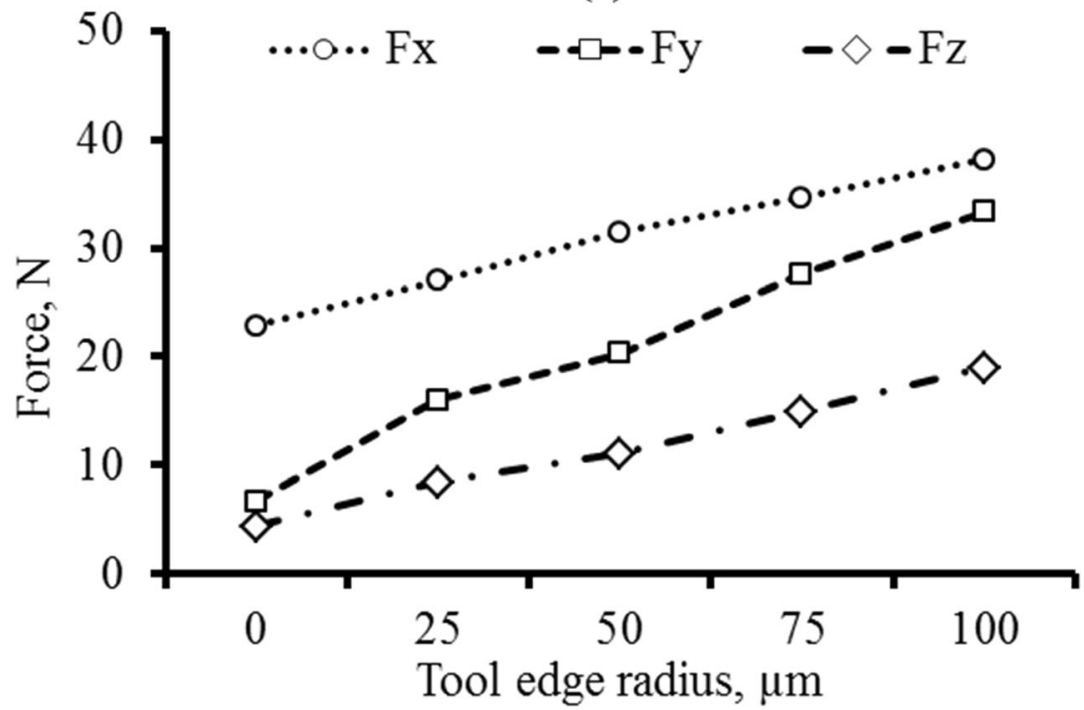

(b) 
moved away from the chip; and (d) withdrawal phase, the insert completely disconnected from the chip. The spreading of stress was transient in one complete cycle of vibration in HT as presented in Fig. 33c, d.

At the engagement phase in HT, the peak stress level reached nearly $810 \mathrm{MPa}$ resulted a lower stress magnitude (by approx. $200 \mathrm{MPa}$ ) compared to CT. The application of externally applied heat to the workpiece reduces its yield point; henceforth, lower energy is required. Similarly, the magnitude of extreme stress level dropped to $415 \mathrm{MPa}$ in the retraction phase (see in Fig. 33).

\subsection{D vibration analysis}

In HT, vibration can be applied on the insert in feed, radial, or tangential directions. In all covered experimental work in the current study, one directional vibration in the velocity direction was applied and was verified with the FE model. Also, the obtained results showed that vibration in the tangential direction had a favorable outcome on cutting forces [24]. However, a study of $2 \mathrm{D}$ vibrational analysis is lacking in literature using FE simulations. The developed model possesses the ability to simulate $2 \mathrm{D}$ and $3 \mathrm{D}$ vibration superimposed on the insert. However, the current work is limited to 2D vibration analysis in HT.

The obtained results showed that $1 \mathrm{D}$ vibrations in axial and radial directions drive the insert to indent the machined surface in relevant direction resulting peak force levels in both cases. Additionally, the insert is partially in contact with the workpiece in the withdrawal phase resulted a minimal drop in the tangential force component and negative values of $F_{y}$ and $F_{z}$, as shown in Fig. 34. This denting of the workpiece yielded superior level of $F_{y}$ and $F_{z}$. The level of $F_{x}$ was 52 and $42 \mathrm{~N}$, respectively, with vibration imposed on the insert in radial and feed direction which is still higher when compared to the level of $F_{x}$ obtained in HT. The use of elliptical vibration on the insert caused a minimal drop in $F_{x}, F_{y}$ and $F_{z}$ as compared to HT (see Fig. $34 \mathrm{~d}$, e). Minor fluctuation in $F_{y}$ was noted during the retraction stage in $\mathrm{XY}$ mode of vibration.

Hence, application of tangential vibration on the cutting insert leads to a superior force reduction in HT and is more favorable for the cutting process of Ti-15333 as 2D mode vibration needs more complexity in machining setup. However, the final conclusions cannot be based only on $F_{x}$, $F_{y}$ and $F_{z}$ comparison, as other factors, such as machined surface quality, should also be examined.

\section{Conclusions}

In the current study, CT, HCT, and HT are used to explore cutting forces and process zone temperature both

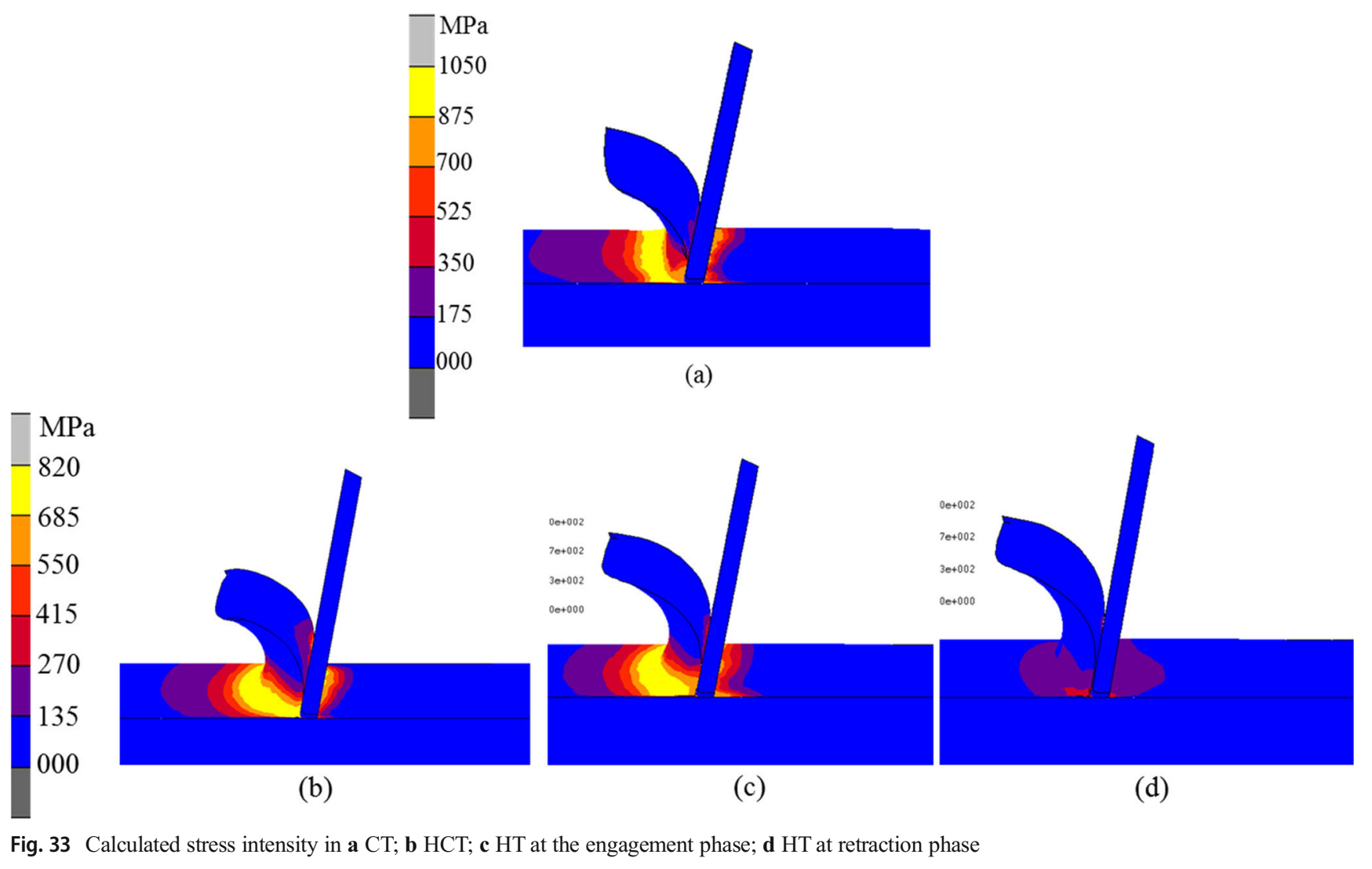


Fig. 34 Forces at studied modes: a tangential vibration, $\mathbf{b}$ radial vibration, $\mathbf{c}$ axial vibration, $\mathbf{d}$ elliptical vibration (XY-mode), e average cutting forces

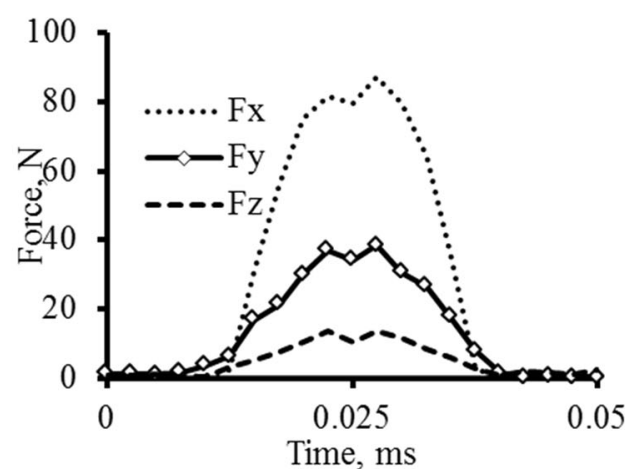

(a)
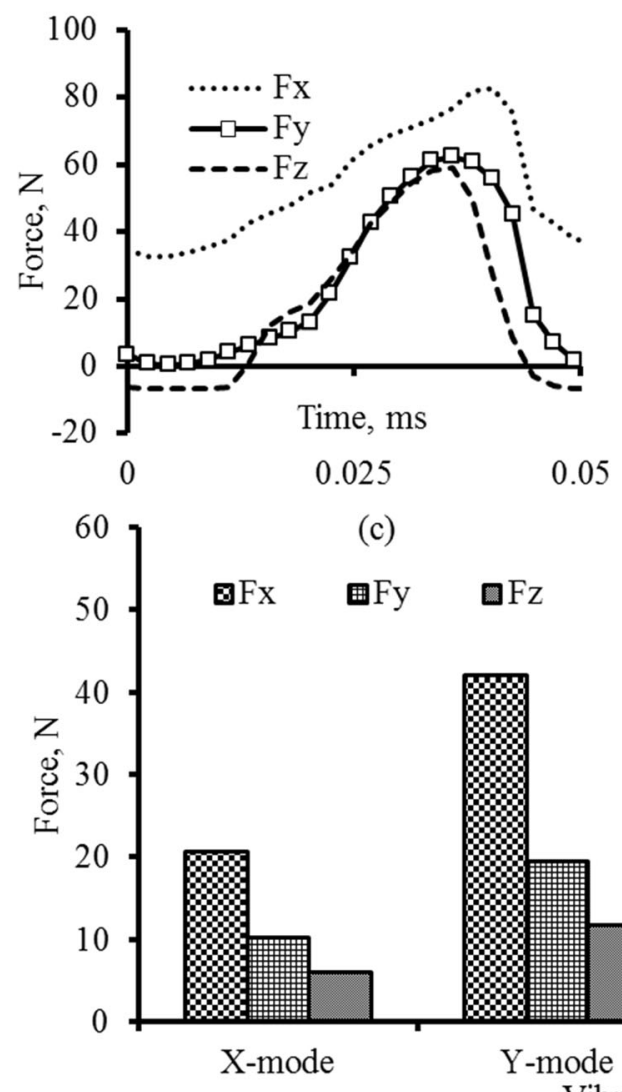

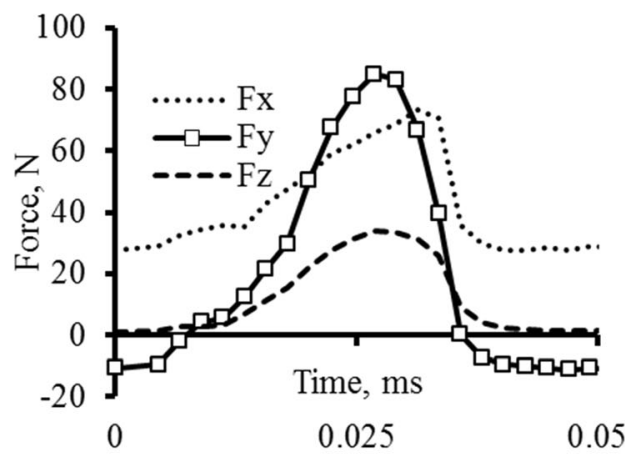

(b)

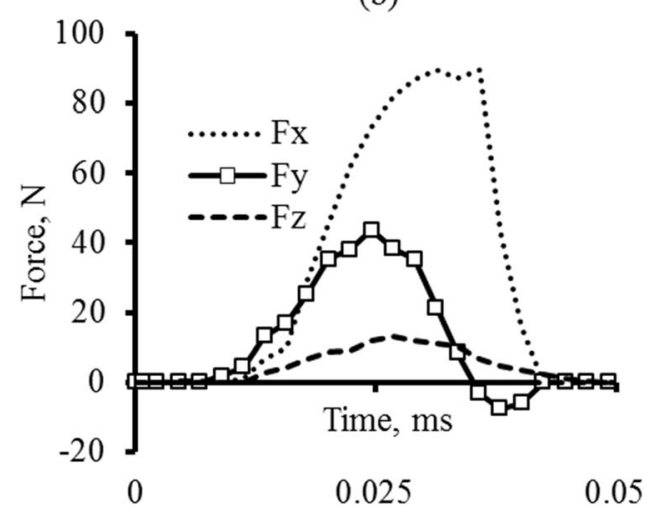

(d)

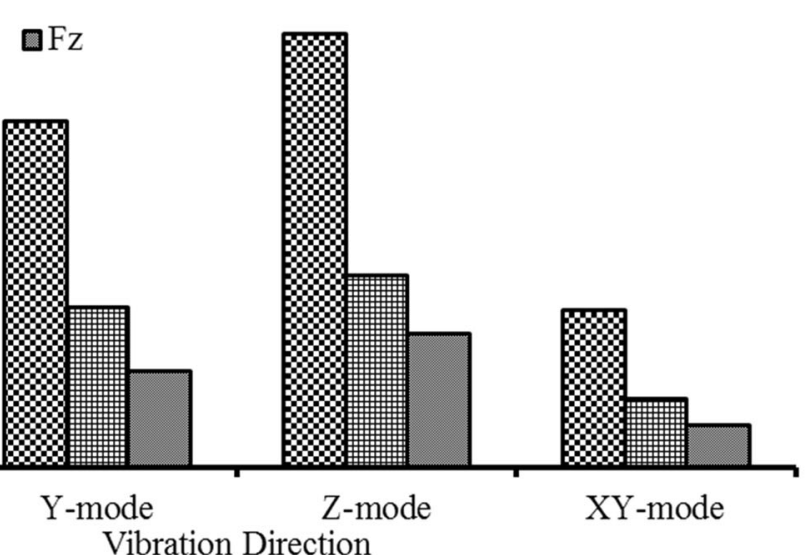

(e)

experimentally and numerically. The studied HT process is an attractive tool for the industries where machinability of Ti alloys is extensively involved. The HT process can be used to get good surface quality with minimum average cutting forces even at rough cutting. The studied alloy demonstrated no metallurgical effect due to the imposed vibration and heat. However, for implementation of the developed process in other grades of Ti alloys, the sensitivity of the alloys with temperature should be investigated prior to shifting toward this process. Further findings of the work are summarized below:
- A new hybrid-turning process is explored for cutting forces and temperature.

- The level of process zone temperature is high in HT as compared to HCT and CT.

- A substantial drop in $F_{x}, F_{y}$, and $F_{z}$ was achieved with the hybrid turning process

- The application of vibration in tangential direction resulted better performance compared to radial and axial modes of vibration in HT.

- The application of external heat and vibration has no adverse effect on the machined product. 
- A superior surface quality was achieved in HT in machining of Ti-15333 as compared to CT.

Acknowledgements The authors would like to acknowledge funding received for the current work under MAMiNa Grant.

Publisher's Note Springer Nature remains neutral with regard to jurisdictional claims in published maps and institutional affiliations.

\section{References}

1. Peters M, Leyens C (2002) Titanium and titanium alloys. Wiley$\mathrm{VCH}$, Germany

2. Zlatin N, Field M (1973) Titanium. Titanium Sci Technol 1:489503

3. Arrazola PJ, Garay A, Iriarte LM, Armendia M, Marya S, Le Maître F (2009) Machinability of titanium alloys (Ti6Al4V and Ti555.3). J Mater Process Technol 209(5):2223-2230

4. Machai C, Biermann D (2011) Machining of $\beta$-titanium-alloy Ti$10 \mathrm{~V}-2 \mathrm{Fe}-3 \mathrm{Al}$ under cryogenic conditions: cooling with carbon dioxide snow. J Mater Process Technol 211(6):1175-1183

5. Donachie MJ (2004) Titanium- A technical guide, 2nd edn. ASM International, Ohio, USA

6. Siemers C, Laukart J, Zahra B, Rösler J (2011) Development of advanced and free- machining alloys by micrometer-size particle precipitation. Mater Sci Forum 690:262-265

7. Muhammad R, Hussain MS, Maurotto A, Siemers C, Roy A, Silberschmidt V (2014) Analysis of free machining of $\alpha+\beta$ Tialloy using conventional and ultrasonically assisted turning. J Mater Process Technol 214(4):906-915

8. Maurotto A, Siemers C, Muhammad R, Roy A, Silberschmidt V (2014) Ti alloy with enhanced machinability in UAT turning. Metall Mater Trans A 45(6):2768-2775

9. Ezugwu E, Da Silva RB, Bonney J, Machado AR (2005) Evaluation of the performance of CBN tools when turning Ti6Al-4V alloy with high pressure coolant supplies. Int J Mach Tools Manuf 45:1009-1014

10. Shokrani A, Dhokia V, Newman ST (2012) Environmentally conscious machining of difficult-to-machine materials with regard to cutting fluids. Int J Mach Tools Manuf 57:83-101

11. Byrne G, Scholta E (1993) Environmentally clean machining processes - a strategic approach. CIRP Ann Manuf Technol 42(1): $471-474$

12. Rahman Rashid RA, Sun S, Wang G, Dargusch MS (2012) An investigation of cutting forces and cutting temperatures during laser-assisted machining of the Ti-6Cr-5Mo-5V-4Al beta titanium alloy. Int J Mach Tools Manuf 63:58-69

13. Babitsky VI, Kalashnikov AN, Meadows A, Wijesundara AAHP (2003) Ultrasonically assisted turning of aviation materials. J Mater Process Technol 132(1-3):157-167

14. Shamoto E, Moriwaki T (1994) Study on elliptical vibration cutting. CIRP Ann Manuf Technol 43(1):35-38
15. Brehl D, Dow T (2008) Review of vibration-assisted machining. Precis Eng 32:153-172

16. Sharman A, Bowen P, Aspinwall D, Dewes C (2001) Ultrasonic assisted turning of gamma titanium aluminide. Rolls-Royce PLC, https://books.google.com.pk/books/about/Ultrasonic Assisted Turning_of_Gamma_Tit.html?id=KSwGMwEACAAJ\&redir_esc $=y$

17. Astashev VK, Babitsky VI (1998) Ultrasonic cutting as a nonlinear (vibro-impact) process. Ultrasonics 36(1-5):89-96

18. Muhammad R, Roy A, Silberschmidt VV (2013) Finite element modelling of conventional and hybrid oblique turning processes of titanium alloy. Procedia CIRP 8:509-514

19. Muhammad R, Demiral M, Roy A, Silberschmidt VV (2013) Modelling the dynamic behaviour of hard-to-cut alloys under conditions of vibro-impact cutting. J Phys Conf Ser 451:1-11

20. Maurotto A, Muhammad R, Roy A, Silberschmidt VV (2013) Enhanced ultrasonically assisted turning of a $\beta$-titanium alloy. Ultrasonics 53(7):1242-1250

21. Muhammad R, Maurotto A, Roy A, Silberschmidt VV (2012) Ultrasonically assisted turning of Ti-6Al-2Sn-4Zr-6Mo. J Phys Conf Ser 382:012016

22. Muhammad R, Ahmed N, Roy A, Silberschmidt VV (2012) Turning of advanced alloys with vibrating cutting tool. Solid State Phenom 188:277-284

23. Muhammad R, Ahmed N, Roy A, Silberschmidt VV (2012) Numerical modelling of vibration-assisted turning of Ti-15333. Procedia CIRP 1:347-352

24. Babitsky VI, Mitrofanov AV, Silberschmidt VV (2004) Ultrasonically assisted turning of aviation materials: simulations and experimental study. Ultrasonics 42(1-9):81-86

25. Muhammad R (2013) Hot ultrasonically assisted turning of Ti$15 \mathrm{~V} 3 \mathrm{Al} 3 \mathrm{Cr} 3 \mathrm{Sn}$ : experimental and numerical analysis. In: Wolfson school of mechanical and manufacturing engineering. Loughborough University, https://dspace.lboro.ac.uk/dspace-jspui/ bitstream/2134/.../Thesis-2013-Muhammad.pdf

26. Dodonov A, Siemers C, Rosler J (2009) Analysis of the processing and machining characteristics of Ti15V3Al3Sn3Cr alloy. In: 7th International Conference on Modern Practice in Stress and Vibration Analysis. Cambridge, UK

27. Muhammad R, Ahmed N, Shariff YM, Silberschmidt VV (2012) Finite-element analysis of forces in drilling of Ti-alloys at elevated temperature. Solid State Phenom 188:250-255

28. Muhammad R, Maurotto A, Roy A, Silberschmidt VV (2012) Hot ultrasonically assisted turning of $\beta$-Ti alloy. Procedia CIRP 1:336-341

29. Lei S, Shin YC, Incropera FP (1999) Thermo-mechanical modeling of orthogonal machining process by finite element analysis. Int $\mathrm{J}$ Mach Tools Manuf 39(5):731-750

30. Li Z, Lambros J (1999) Determination of the dynamic response of brittle composites by the use of the split Hopkinson pressure bar. Compos Sci Technol 59(7):1097-1107

31. Demiral M, Roy A, Silberschmidt VV (2010) Effects of loading conditions on deformation process in indentation. Comput Mater Contin 475(1): 1-18

32. Shi J, Richard CL (2004) The influence of material models on finite element simulation of machining. J Manuf Sci Eng (T ASME) 126: 849-857 